\title{
WestVirginiaUniversity
}

THE RESEARCH REPOSITORY @ WVU

Graduate Theses, Dissertations, and Problem Reports

2012

\section{Improvisation and Visual Thinking Strategies In Art Education}

Jason Jaros

West Virginia University

Follow this and additional works at: https://researchrepository.wvu.edu/etd

\section{Recommended Citation}

Jaros, Jason, "Improvisation and Visual Thinking Strategies In Art Education" (2012). Graduate Theses, Dissertations, and Problem Reports. 458.

https://researchrepository.wvu.edu/etd/458

This Thesis is protected by copyright and/or related rights. It has been brought to you by the The Research Repository @ WVU with permission from the rights-holder(s). You are free to use this Thesis in any way that is permitted by the copyright and related rights legislation that applies to your use. For other uses you must obtain permission from the rights-holder(s) directly, unless additional rights are indicated by a Creative Commons license in the record and/ or on the work itself. This Thesis has been accepted for inclusion in WVU Graduate Theses, Dissertations, and Problem Reports collection by an authorized administrator of The Research Repository @ WVU. For more information, please contact researchrepository@mail.wvu.edu. 


\title{
Improvisation and Visual Thinking Strategies In Art Education
}

\author{
Jason Jaros \\ Thesis submitted to the School of Art and design \\ At West Virginia University \\ in partial fulfillment of the requirements \\ for the degree of \\ Master of Arts \\ In \\ Art Education \\ Victoria J. Fergus, PhD Chair \\ Jerry McGonigle, MFA \\ Kristina Olson, MA \\ School of Art and Design \\ Morgantown, West Virginia \\ 2012
}

Keywords: art education; spontaneity; performance 


\section{Abstract \\ Improvisation and Visual Thinking Strategies \\ In Art Education \\ Jason Jaros}

This study examines the characteristic elements and possible educational benefits of spontaneity and improvisation in visual art education. The research draws from current practices and philosophies in music and drama education with the aim of developing collaboration, communication, problem solving, and creative and innovative thinking skills in students through the experience of making and appreciating art involving activities that encourage spontaneous decision making. Visual Thinking Strategies and the six continua for assessing thinking serve as the tools with which to investigate the effect of these activities on interpretive narratives of 40 fourth grade students in a public school setting. 


\section{Table of Contents}

Abstract..........................................................

List of Images..............................................

List of Figures...................................................... vii

Chapter 1: Introduction........................................1

Chapter 2: Theory and Improvisation in the Arts..................14

Chapter 3: Applications of Improvisation.....................22

Chapter 4: Visual Thinking Strategies; Children and their Stories...32

Chapter 5:Findings and Conclusions.......................... 36

Bibliography...............................................68 


\section{List of Images}

1. Student work from Systematic drawing Exercise, Untitled,

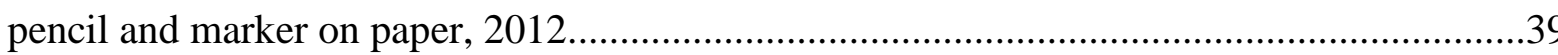

2. Student work from Systematic drawing Exercise, Untitled,

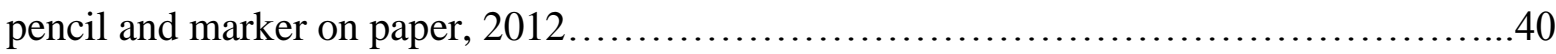

3. Student work from Systematic drawing Exercise, Untitled,

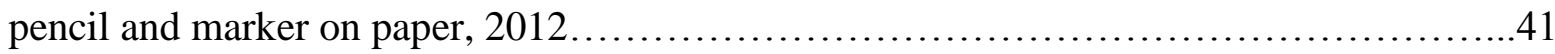

4. Student work from Systematic drawing Exercise, Untitled,

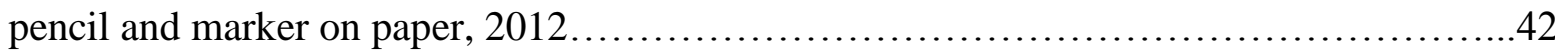

5. Student work from Shadow Puppet Exercise, Untitled, Mixed media on paper, 2012

6. Carmen Lomas Garza. Curandera (Faith Healer). Oil on Linen mounted on wood, Collection of Mexican Museum, San Francisco, CA. c.1989 Carmen Lomas Garza. Used with permission from VTS Basic Manual Grades 3-5.................55

7. David Bradley. Chippewa Family. 1987. Acrylic on canvas, From the Collection of the Plains Art Museum, Fargo, ND 


\section{List of Figures}

1. Table diagram: the Six Continua for Assessing Thinking.............................66

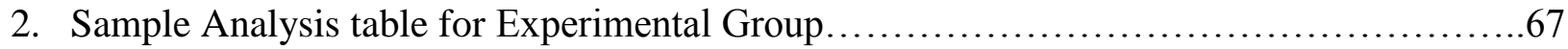

3. Sample Analysis table for Control Group.......................................68

4. Writing Samples for Experimental group, Image \#1 .............................69-70

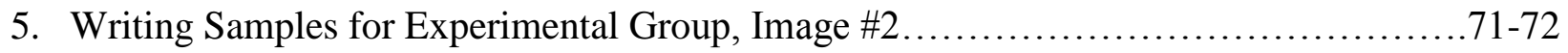




\section{Chapter 1: Introduction}

My background as an art teacher and a musician first compelled me to consider the idea of incorporating improvisation into my art education curriculum. Though equally passionate about art and music, the ways in which I've studied and experienced them are vastly different. As a musician coming from the school of folk process and having a limited knowledge of music theory I approach art and music from opposite directions, but I find common ground between them with improvisation. Risk taking, experimentation, allowing a piece to develop or deteriorate, not knowing where I will go next has allowed me to learn what works and what doesn't work for me. "Yet surely the only way we are going to come to any grasp of emotions in the living situation is to be aware of them under experimental and imaginative conditions" (Hodgson, 1966, p. 23). Improvising allows us to survive, adapt, and learn. The extent to which we learn through improvisation depends on how receptive we are to the sounds, images, and interactions in the world around us as well as in any imaginary world.

Art and art making can be defined by three different models: a system of production, a system of communication, and a system of critical reflection (Pearse, 1983, p.158). A strong visual arts program should not only enlighten students about techniques, elements and principles of design, art history, cultural and self-awareness, and interpretation, but should also supply them with the thinking skills they need to be successful in the future. Learning and innovation skills such as critical thinking, problem solving, creativity, communication, and collaboration are part the $21^{\text {st }}$ Century Skills map which is a current focus of policy reform in education. The NAEA, National Arts Education Association's Advocacy White Papers for Art Education, calls for an "adaptable curriculum framework" that is "thus able to network information about human experience, serving as a catalyst for innovation and invention in learning" (Rolling "State of Play" 2008). Could elements of improvisation be adapted to encourage innovative creative thinking and communication skills in students as they make sense of their visual 
world? The purpose of this study is to test and answer this question.

Improvisational exercises are commonly used in elementary music education programs, and are included in both the national music education content standards and objectives and the West Virginia $21^{\text {st }}$ century music education content standards and objectives. Though improvisation is not mentioned, the requirement to compare visual, aural, oral, and kinetic elements in dance, music, theatre, and visual art is evident as it is listed as a requirement in the West Virginia Visual Art Education Fourth grade content standards and objectives. This research aims to take this one step further by not only "comparing" these elements, but incorporating them, particularly the characteristic elements of improvisation and play, to the art curriculum. Research on improvisation in general is limited, but within the context of visual art education it is nearly nonexistent leaving this topic of study wide open for questioning. There is, however, within the discipline of music education, research suggesting its importance. According to the music educational resource Music in Childhood; From Preschool through Elementary Grades: “Opportunities to improvise should occur throughout children's development, stimulating them to converse in music the same way they converse using words - freely and spontaneously with meaning.’(Campbell \& Scott-Kassner, 2006, p. 253)

If these opportunities are important in the development of a musical language then why would they be any less important in the development of a visual language? The purpose of this study was to explore the idea of using elements of improvisation in visual art education to provide opportunities for children to experience art in a way that challenges them to be spontaneous, think critically, and develop communication skills. 


\section{Significance of this Research}

It is clear that educators must be conscious of the needs of their students due to the fact that individuals learn in a variety of ways. In my opinion, merely presenting content in different ways to address these learning dispositions without providing opportunities to experience it creates a culture of dependent learners. According to Hodgson, "Improvisation is a means of training people to think. It aims at the inclusion of clear mental habits and the training of the expression of these thoughts in a concise and orderly way.... it calls for fairly quick thinking and at times for different levels of thought at one and the same time" (Hodgson, 1966 p.22). For example, when a student is presented with a problem in math or science, they expect to be told or shown how to solve it. However, within the context of drawing or painting, there is no one rule or formula, and the concept of finding or creating a way to express an idea can be intimidating to some students. The utterance of the dreaded words "I can't" or "I don't know how" are all too familiar to art teachers. The attitude of uncertainty, fear of failure, leading to the unwillingness to explore possibilities is one that will prevent a student from recognizing his or her full potential.

The training of actors in improvisational theater, intends to relieve tensions by focusing on the powers of concentration and observation in order to gain a self-awareness enabling the student actor to "not only experience but also see this experience in relation to other things and people" (Hodgson, 1966, p.23-24). The training of musicians in improvisation aims to allow them to experience music making in a unique way, by simultaneously combining and applying to an instrument decision making skills, anticipation, and structural thought in real time (Monk, 2010, p.40). The training of young artists in improvisation, in this study, intends to follow suit by providing opportunities for unique experience, 
play, storytelling, problem finding, divergent thinking, collaboration, and communication in order to further the development of a visual language.

Improvisation is usually defined by context. Improvisation in drama aims to utilize the two elements from everyday life: the spontaneous response to the unfolding of an unexpected situation, and the ingenuity called upon to deal with the situation; both of these are needed in order to gain insight into problems presented (Hodgson, 1966, p.2). According to Russian actor and theater director Constantine Stanislavski, improvisation provides a platform to explore performance and the narrative form and to develop important life skills (creativity, spontaneity, teamwork, listening, perception, trust, generosity and openness) (Spolin, 1977, p.12). In the context of music, it has been commonly defined as the spontaneous creation of music in the course of extempore performance or as the creative activity of immediate ("in the moment") musical composition, which combines instrumental technique as well as spontaneous response to other musicians. Though there are differences between these two disciplines, when concerning improvisation the act of responding spontaneously (opposing the contrived, arising from momentary impulse) is mentioned as an integral part of the puzzle in both.

The definition of improvisation in the context of visual art references more of an internalized activity. It is characterized through the works and philosophies of artists such as Wassily Kandinsky, Jackson Pollock, Joseph Beuys, and Robert Rauschenberg who made significant connections between art, music, and performance. The problem here and perhaps why this subject has been avoided in educational literature, is the notion of product creativity being associated with visual art. In the visual arts, improvisation occurs during the art making process as the artist has time to spontaneously change and alter a piece, but it goes unnoticed as the focus is often placed on the 'object' created rather than the 'work' that created it (Sawyer, 2000, p.150). This internalized improvisation in the creation of art is 
important, but the focus here is also about encouraging an externalized type of improvisation, by bringing in elements from the disciplines of drama and theater to enhance the child's experience of art from different perspectives. 


\section{An Overview of the Study}

This study was conducted with two fourth grade classes to explore the idea of adapting improvisation into an art education curriculum as an opportunity for children to experience art in a novel way. Drawing from the disciplines of music and theater, activities were designed with the characteristics of improvisation in mind. It is important to recognize the structures within which improvisers work and how they can be translated across disciplines. In an article from the Journal of Aesthetics and Art Criticism 2000, Keith Sawyer uses five characteristics of improvisation to compare the theories of John Dewey and R.G.Collingwood concerning the creative process as improvisation. By acknowledging some of these improvisational characteristics and deliberately designing activities that encourage students to improvise within these structures the project aimed to provide challenging and possibly beneficial opportunities for students. Each activity designed in this study draws upon these characteristics to serve as the foundation for an improvisational art unit. Sawyer states them as;

1. An emphasis on creative process rather than creative product

2. An emphasis on creative processes that are problem finding rather than problem solving

3. The comparison of art to everyday language use

4. The importance of collaboration with fellow artists and with the audience

5. The role of the ready-made or cliché in art (Sawyer, 2000, p.152)

Improvisation has a long history ranging from primitive ritual to present day happenings. All art forms have begun with improvisation. The early narrative epics like the Odyssey and the Iliad began as improvised story telling. Song and dance and early dramatic ritual took on a more formal shape after long periods of improvisation. Improvisation has found its way into quite a variety of aspects of programs for actors, in business, vocational courses, in the training of teachers, in psychotherapy, and many facets of education. Over and over again its value in one field or another has been indicated. (Hodgson, 1966, p.2).

For this study, Visual Thinking Strategies were implemented to engage students while promoting creative improvised responses to images serving as the vehicle with which to investigate the component of this project. Visual Thinking Strategies (VTS) resulting from over fifteen years of 
collaboration between cognitive psychologist Abigail Housen, and veteran museum educator Philip Yenawine, is a research-based teaching method that improves critical thinking and language skills through discussions of visual images. It encourages participation and self-confidence, especially among students who struggle. On a basic level, VTS challenges students to not only respond to visual images, but also to provide evidence and support for their assumptions and interpretations while continuing to explore further. The introductory protocol for VTS asks three questions: What is going on in this picture? What do you see that makes you say that? What else do you see?

One of the purposes of art, or reasons why we make art, is to tell stories. The trend of research on VTS follows a long range model, conducted over the course of several months or years, as the method functions on multiple levels ranging from beginner to advanced. For this study, the beginning level considered to be narrative based, was intermittently dispersed within a five week improvisation unit conducted in a public school setting. The students were exposed to this method of collaborative interpretation in conjunction with improvisational activities and games, data collected from pre and post writing samples was analyzed using the six continua for assessing thinking and showed some change, though insignificant at this point in the creative thought process which will be discussed later as a topic for further investigation. 


\section{Methodology}

Research methodology for this study required the gathering of qualitative data in the form of writing samples, observations, and student self-reflection surveys to determine whether or not the inclusion of elements of improvisation into an art curriculum would be beneficial to the development of thinking skills in elementary students. By drawing upon this data I hoped to shed some light on the overall experiences of the students involved in the study as well as some of the following questions: How can improvisation be adapted to fit into an art education curriculum? What, if any, changes in creative thought processes will occur as a result of these experiences? What effect will these experiences have on the collaborative, communication, and interpretive skills of the students?

Examining the procedures, objectives, and assessment of improvisation in the disciplines of music education and drama/theater education contributed to the design of this study. Drawing upon these resources as well as innovative practices in foundations curriculums in higher level art education such as "State of Play 2009" a product of the Integrative Teaching International Think Tank, and the use of Visual Thinking Strategies, the design of this research is unique. 


\section{Study Design}

The improvised narrative and the experience of art through improvisation served as the foundation for the design of activities implemented in a forty day experiment conducted in two fourth grade classes at two different public schools in West Virginia. A state-mandated program in West Virginia, Writing across the Curriculum, requires a writing component to be implemented into every subject area including art and music, and having two groups of students, one serving as the experimental group and one as the control group, provided the opportunity to compare creative writing samples. Each group provided a preliminary writing sample to establish a baseline as well as a secondary sample at the conclusion of the unit. The experimental group participated in the improvisational activities while the control group provided only two writing samples within the same designated time frame having no involvement in the improvisation (VTS) activities. 


\section{Timeframe and Procedures}

\section{Experimental Group A}

1. Day 1(Pre) Writing Sample: Students were shown an image and were asked to write the "Story" of the picture. These writing samples were collected, assigned a number corresponding to each individual student, and stored in a secure location.

2. Day 2-3: Students were introduced to Visual Thinking Strategies. Each day a series of 2-3 images were the basis of classroom discussion, where students were asked "What is going on in this picture? What do you see that makes you say that? What else do you see?" Images Discussed: VTS "Learning to Think and Communicate through Art” Basic images Grades 3-5 (see Appendix)

3. Day 4-5: Improvisation activity 1- Systematic Drawing: This activity aims to place an emphasis on the process of drawing rather than the product. Students created a drawing using a limited number of shapes and line types. The rolling of dice determined what kind and how many shapes or line types the students were able to use in their piece within a limited time frame of 10-20 seconds. They rolled the dice 20 times and were to add shapes and lines accordingly after each roll. A class discussion of the activity took place at its conclusion.

4. Day 6 VTS training: continue with class discussions of images asking the same questions with slight variation. For example: Where is this happening? Why is the artist showing us this?

5. Day 7-9 Improvisational Activity 2: Collaborative Product Oriented Shadow Puppet piece: In Groups of 4-5, Students created shadow puppets with their hands and with some found object props (which were supplied by investigator) to narrate a piece of music. 
Two students at a time made the shadow puppet characters using the light from a projector shining on a large piece of paper. The music would stop at random times and the students had to freeze their hands and props in place. The other students in the group would then trace the outline of the shadow puppet with pencils and then switch positions. The paper would then be turned clockwise and the exercise continued until the paper was covered with the contour shapes. Students then worked together adding color with paint, pastels, and crayon to create an abstract collaborative work of art.

\section{Day 10 VTS Training}

7. Day 11-13 Improvisation Activity 3: "I am the Artist Game" Ricochet Critique: Students were organized in groups of 5-6. Without seeing the image, one student chose at random an artwork from a pile and had 1 minute study it. Within that time frame, the student would come up with a title for the piece then present it to the class saying "I am the artist of this piece and I call it....” At this point the other students in the group would begin to ask questions about the work. The "acting" student would then come up with improvised responses to the questions as the artist.

\section{Day 14: VTS Training}

9. Day 15-18 Improvisation activity 4: story starters: Using an online resource (Scholastic Story Starters) each student used the story starter machine to come up with an idea for a story. The students used this as the basis for an illustration.

10. Day 19 VTS training

11. Day 20 (Post) writing sample: Students will be shown an image and will be asked to write the "Story" of the picture. These writing samples will be collected, assigned a number corresponding to each individual student, and stored in a secure location. 
Control Group B: This group did not participate in any of the VTS or Improvisational activities. They participated in regular instructional activities not related to the project. There was a 20 day period between the pre/post collections of writing samples.

1. Day 1(Pre) Writing Sample: Students were shown an image and were asked to write the "Story" of the picture. These writing samples were collected, assigned a number corresponding to each individual student, and stored in a secure location.

2. Day 20 (Post) Writing Sample: Students were shown an image and were asked to write the "Story" of the picture. These writing samples were collected, assigned a number corresponding to each individual student, and stored in a secure location. 


\section{Data Analysis}

Harvard Project Zero, an educational research group at the Harvard Graduate school of Education credited for the development of the Artful Thinking Approach provides a way for teachers and students to identify qualities of thinking with the Six Continua for Assessing Thinking. (See appendix) Very closely related to Visual Thinking Strategies, the Artful Thinking Approach aims "to help teachers create rich connections between works of art and topics they are teaching; and to use the power of art as a force for developing students' thinking dispositions"(Tishman, 2006, p.6). The writing samples collected in this study were assessed by using the six continua to analyze the depth of thinking demonstrated by the students as they were asked to tell the story of an image. To dismiss any bias on the part of the investigator, the samples were also scored by the classroom teachers of each group of students and then averaged. For each quality represented on the Continua, the samples were given a number (1-4) to identify the level of thought perceived by the teachers. The teachers were also given copies of the images associated with each group of samples. The number of each sample was coded in a random order to ensure an unbiased assessment between the preliminary and secondary examples. A comparison between the preliminary and secondary scores was made within the experimental and control group as well as between the two groups. 


\section{Chapter 2: Theory and Improvisation in the Arts}

Because of the nature of improvisation the question of whether or not it can even be taught, as well as its relevancy has been debated. To first understand how to approach the subject in visual art education, I felt it necessary to explore the relationship between theory and practice and the role of improvisation in the creative process. 


\section{Improvisation: Can it be taught?}

At present, there is very little writing on improvisation and most of that has emerged within the music practice, usually written by musicians, as well as within the area of dance where improvisatory techniques are central. By placing an emphasis on self-expression and collective interaction the musical account of improvisation, while important has proved less engaged with the particular structure of improvisation. One of the intended aims of the current research is to both broaden this perspective while offering a more theoretically sophisticated model of improvisation that reflects more accurately the particularity of aesthetic production across the disciplines and which draws upon primary, although often ignored, aspects of contemporary theory. (Peters, 2005, p. 300).

The problem of relating theory to practice within the context of improvisation discusses the components and value of two improvisational models; Autonomy and Heteronomy. The basis for this discussion lies in the debate between arts educators as to which histories, theories, and methodologies are most relevant to the studio artist. The autonomy model places emphasis on free improvisation which promotes both positive and negative freedoms; "freedom to" and "freedom from" The idea here is to challenge the students to break away from the security of rote learning to enable them to develop to their fullest potential as a direct route to self-expression. This model would be an unstructured approach to improvisation on which Peters is quoted as saying "On the one hand thought negatively, improvisation is a means to an end, a way of loosening up, or indeed challenging educational structures with a view to arriving at educational strategies that are more responsive to current technologies, actually more about education than improvisation perse. On the other, improvisation is promoted, positively, as a valuable end in itself, as something to be taught. And this is the problem, whether it be as a way of teaching or the subject of teaching, improvisation, as described above, is, if not unteachable, then excruciatingly difficult to teach" (Peters, 2005, p.302). 
Heteronomy refers to action that is influenced by a force outside the individual. This model of improvisation has more to do with the "making" of the art work. This internalized process of improvisation is described by peters as, "The improvisation that passes unnoticed, the ongoing work of the art work, the trial and error, the simple and not so simple pleasures of distraction... this takes place within given structures that over determine the play of the familiar and the unfamiliar, the expected and the unexpected, the intention and the accident" (Peters, 2005, p. 303).

Both models present the teacher with questions of how to approach improvisation in the classroom. At the early stages in the development of this project, the intention was to focus on teaching children to improvise, which proved to be a futile effort, resulting in either a chaotic mess or blank stares and awkward silence (Autonomy). Unknowingly, children improvise every day, but drawing attention to that process, emphasizing it, and making them aware of it seemed to have deconstructive implications (Heteronomy). Although Peters argues that improvisation cannot be taught, Augusto Monk in his article "Improvisation and Cognition 2010" disagrees. He is quoted from this article as saying;

Misinterpreting the concept of improvisation is overlooking what improvisation can contribute to the learner's musical development. This discussion assumes that improvisation is a skill that (a) can be learnt, taught, and nurtured; (b) is not stylespecific; and (c) is a form of music making as opposed to a means to an end (as it is not rare to read about the benefits of improvisation in other areas of musical training). It has been argued that improvisation reinforces sight-reading, music analysis, and performance of prepared repertoire. Although this is all true, I argue that the purpose of improvisation is to make music. Improvisation is a significant contribution to music curricula not because it improves other areas of training, but because it allows musicians to experience music making in a unique way. (Monk, 2010, pg. 40).

Monk goes on to say that three cognitive skills which can be isolated and nurtured (decision making, anticipation, and structural thought) work together simultaneously when a musician improvises. These skills are also valuable to the visual artist, so using improvisation in a way that provides the student opportunities and choices to improvise within a structure seemed to be the next 
logical step. Artist, musician, and teacher, Michael Pestel, on teaching improvisation in visual addresses the value of both models as well as the important role of the facilitator and is quoted as saying,

Improvisation in the visual arts is most similar to improvisation in music. It comes in different degrees, all of which serve a purpose. On one end of the spectrum, the teacher offers students specific ideas or a conceptual structure within which to explore visual phenomena and concepts spontaneously. On the other end, the teacher gives little or no guidelines and allows the student to intuitively or unconsciously create his or her own structure. Both the structured and the freeform approach have their place. What students learn from these experiences depends upon their openness and the teacher's skill in leading a group discussion ("show and tell" about the work afterwards). (Michael Pestel, from conversation)

It appears that both models have value and serve a purpose. Taking what has been learned through this discussion of the theories and practices of writers and artists, it seems as though a balance must be obtained concerning parameters and the allowance for children to create a structure within which to improvise. Pestel refers to the relationship of improvisation in visual art to the processes closely observed in the discipline of music, but due to the internalized nature of improvisations described in the heteronomy model, which would be difficult to study, it is important to further investigate the characteristics of improvisation to more clearly define an approach to using in visual art education. 


\section{Improvisation and the Creative Process: Sawyers Five Characteristics}

1. An emphasis on creative process rather than creative product

I recently had a conversation in passing with an educator from another school. When I mentioned I was an art teacher, she made a comment about how nice it would be to not have to worry about testing and to be able to cut, paste, color, and make crafts all day. Quickly assessing the situation, our conversation ended abruptly, but I began to think about how art education is perceived by people. More often than not art class is thought of as a place where kids just "make" stuff, a product; a painting, a self-portrait, a print, a little clay sculpture of an imaginary animal, something to take home and put on the refrigerator. The distinction between process and product based art is very clear. Product based projects can be described as "cookie cutter" activities such as coloring pages or "activity kits" yielding homogeneous results that have a very low degree of separation as far as individual creativity. Whereas process based projects allow for students to find a more creative means to an end while drawing upon personal and cultural experiences, and individualized artistic decision making. (Stone, Chakraborty 2011, pg.87) Both approaches do indeed lead to a product.

Of course, this "process" leads to a "product" (e.g., something for parents to post on their refrigerator doors), with the latter often epitomizing parents' view of art education. While the product is an important outcome of art education, we contend that teaching the process to students deserves equal emphasis in the classroom. (Stone \& Chakraborty, 2011, pg. 87).

With improvisation, the product is the process, an improvised dialogue between two actors, a performance, a jazz solo, a conversation between brush and canvas internalized by the visual artist. Therefore, the emphasis must be more intently placed on process rather than product and this must be communicated to the students so they don't get discouraged with outcomes. It is important for the 
teacher to present activities in way that make students feel comfortable with the experience and not so focused on the results. Kieth Johnstone in his book “Impro: Improvisation and the Theater" suggests that the instructor "take the blame for failure" in order to ease tensions and encourage the necessary mindset required to improvise. From his book Johnstone writes;

In exchange for accepting the blame for failure, I ask the students to set themselves up in such a way that they'll learn as quickly as possible. I'm teaching spontaneity, and therefore I tell them that they mustn't try to control the future, or to win; and in turn that they're to have an empty head and just watch. When it's their turn to take part they're to come out and just do what they're asked to, and see what happens. It's this decision not to try and control the future which allows the students to be spontaneous. (Johnstone, 1981, p. 32).

2. An emphasis on creative processes that are problem finding rather that problem solving particular characteristic of improvisation provides a great deal of space to experiment within the discipline of visual arts education. As a printmaker in my undergraduate and graduate studies I was exposed to many different philosophies, styles, and approaches to art- making. The problem solvers would have a vision of a final piece incessantly planning and sketching their compositions, and with the execution of the work essentially solving the problem. The problem finders would be constantly experimenting, searching, improvising, and allowing the work to evolve while trying to identify the visual problem.

Personally, I have experienced as an art student should, both creative processes, but as I progressed seemed to be more interested in the problem finding approach. Even though this is the case, I have found as an educator that many of the lessons I teach tend to place more emphasis on creative processes that are problem solving. Perhaps this is due to the structures within which students are accustomed to working. This is not always the case, but often times I follow a similar formula or protocol when teaching a lesson. The students are introduced to the concepts, brainstorm ideas, plan 
compositions, execute the work, and discuss outcomes. This idea of emphasizing problem finding creative processes is exemplified in activities such as systematic drawing which were incorporated into this study.

3-4. The comparison of art to everyday language use \& the importance of collaboration with fellow artists and with the audience

According to Sawyers' analysis, both Dewey and Collingwood perceived art to be like language in a social context, every medium and discipline of art having its own language with which to communicate. Speech being a familiar means of communication is an art in and of itself, and is more often than not improvised. (Sawyer, 2000, pg.155-156)

Thus the connection with improvisation: In many ways, everyday conversations are also improvised. Especially in casual small talk, we do not speak from a script; our conversation is collectively created, and emerges from the actions of everyone present. In every conversation, we negotiate all of the properties of the dramatic frame- where the conversation will go, what kind of conversation we are having, what our social relationship is, when it will end. In fact, improvisational theater dialogue can best be understood as a special case of everyday conversation. (Sawyer, 2000, p.155).

With this being said one could argue that any time we interact or collaborate with others improvisation will likely occur. Acknowledging this occurrence of improvisation in classroom discussions, group interpretation, and student collaboration is one thing, but for this research the design of activities with the intent to deliberately cultivate it is inherent.

5. The role of the ready-made or cliché in art

The debate of the cliché in art as improvisation centers on the issue of originality, which presents some problems. Both Dewey and Collingwood make the distinction between "art proper" and "false 
art" or "academic and mechanical" rather than "esthetic" (Sawyer, 2000, p. 157). This theory suggests that art must be 100 percent original, which Sawyer refers to as an unrealistically high standard.

"The musician did not invent his scale or his instrument. The painter did not invent the idea of painting pictures or the pigments and brushes with which he paints them... (Artists) become poets or painters or musicians... by living in a society where these languages are current." (Sawyer, 2000, p.157).

This particular debate in relation to the research conducted in this project is one of less importance due to the fact that it focuses more on higher level creative processes. However, one of the activities developed for the study could be considered a ready-made as the students took part in a performance based exercise I call "I am the Artist of this Piece".

In conclusion, the elusive nature of improvisation generates much debate between theorists. Two improvisational models autonomy and heteronomy have value, but each on their own presents the educator with uncertainties. A comprehension of the creative process in relation to improvisation helps to clarify the way in which this process can be acknowledged and applied to a visual arts curriculum. Though it is beneficial to be conscious of this, it is after all only theory. The challenges of teaching in a public elementary school setting present a whole other set of concerns. As stated earlier there is little writing on the subject of improvisation, nearly all of it relating to music and theater. Therefore, to identify more clearly its uses in practical application with children studying art one must look to these disciplines for guidance. 


\section{Chapter 3: Applications of Improvisation}

This chapter addresses the problem of how to adapt improvisation into a visual arts education

curriculum by investigating the common practices and rationales exercised in drama education and elementary music education.

1. How do teachers begin using improvisation?

2. What are the goals, benefits, and reasons for teaching it?

3. What structures are most common and effective when teaching improvisation to young students?

4. How are improvisations assessed and how do students ascribe meaning to them? 


\section{Improvisation in Elementary Education}

\section{Drama}

With the intention of developing innovative creative thinking and communication skills in students through the use of improvisation in art, first we must look at the reasons it is used in other disciplines. Though some schools unfortunately either fail to recognize the importance of drama education at the elementary level, or lack the funding for a program, the amount of developmentally appropriate resources available is astounding. Furthermore, by doing a search online for improvisational drama activities, one will find a plethora of ideas such as improv drama games, scenarios, and ice breakers that aim to develop a performer's creative and quick thinking skills. Improvisation in drama with children draws upon the child's natural disposition for play in order to gain confidence. "Children spontaneously play out different aspects of their experience in ways which enable them to learn and gain reassurance" (Hodgson, 1966, p.3).

In Keith Johnstone's book “Impro, Improvisation and the Theater”, he challenges the traditional system of education by reflecting on his experiences as a student and a teacher. In this exceptional collection of writings, Johnstone's four essays on status, spontaneity, narrative skills, and masks and trance discuss the negative effects of education on creativity. He suggests a number of ways to rediscover one's creative abilities by renegotiating status roles and encouraging free association, play, and humor. In the opening chapter, he credits his art teacher Anthony Stirling for changing his perception of education. After participating in an art activity that was intentionally frustrating to Johnstone, Stirling showed the class examples that were done by a group of eight year olds. "I was speechless. Stirling believed that the art was in the child and that it wasn't something to be imposed by 
an adult. The teacher was not superior to the child, and should never demonstrate, and should not impose values: This is good, this is bad... The implication of Stirling's attitude was that the students should never experience failure. The teacher's skill lay in presenting experiences in such a way that the student was bound to succeed" (Johnstone, 1979, p.20-21). Creating a comfortable environment, appropriate presentation of activities, allowing students to play and have fun, and not imposing values on the outcomes, seem to be important factors when using improvisation in drama. What are its benefits? Hodgson writes, "Improvisation helps the actor's overall confidence and final performance, so, in the learning process, ample experience has indicated that improvised drama, because it aids overall development of the personality, also improves the quality of examination work at all levels. With the highly intelligent, it helps to a surer development on a personal and emotional plane, leading to a more coordinated and balanced person.” (Hodgson, 1966, p.5)

These rationales for teaching with improvisation in drama suggest its value in other areas, not only in the training of actors, but also in the development of one's personality, creative thinking skills, confidence, and even test scores. In drama, improvisation seems to provide for personal growth across disciplines and in life. The influence of drama education on this research is most connected to the development of communication skills and play. For example, during the activity called "I am the artist of this piece" students were provided the opportunity to 'play' the role of the artist as way to experience a work of art. 


\section{Music}

Music is perhaps the most written about discipline concerning improvisation. A study that investigated teachers' perceptions and practices in regards to improvisation found that $81 \%$ of elementary school music educators use it in the classroom. Most commonly, improvisation was used "as a response to a visual, verbal, or audio stimulus and as means of showing emotions, themes, moods and ideas" (Koutsoupidou, 2005, pg. 363). These are five of the most commonly cited rationales for including improvisation in music education; creativity and musical expression, improved musical skills, historical and cultural value, musical social interaction, and opportunities for musical assessment. (Scott, 2007, p.9) The discipline specific nature of these rationales establishes a basis for the inclusion of improvisation by cultivating cognitive skills to further the development of a musical language, but they could also be aligned to serve as rationales for use of improvisation in the visual arts. Because improvisation is typically something that is not thought of when it comes to art education, an understanding of how music teachers begin to use it through exploration may shed some light on how to go about it in visual art.

Beginner improvisers must access improvised music making through exercises, tasks, and collaborative activities that specifically address a cognitive skill to develop; a learner needs clearer guidelines than "make something up with these pitches". Guidelines must provide a clear framework for the player to work within in order to develop the three aspects of cognition that differentiate improvisation from other musical skills. As the beginner gains confidence the tasks can become more open ended allowing more space for creativity and personal input. As with any other musical skill, improvisation requires cultivation and ongoing practice. (Monk, 2010, p.41).

One problematic issue with this project was the lack of previous studies providing structures dealing with improvisation to call upon within the discipline of visual art. As discussed previously, the characteristics of improvisation helped to define important guidelines for the development of activities 
used in this study. Unlike in visual art education, developments concerning the use of improvisation in music education have been thoroughly examined. Ruling out the complete Autonomy model, ( having no guidelines or parameters) as it will likely produce results that are at the very least disorganized and not exactly suitable to a public school environment, a more structured model for using improvisation in music called the Orff Schulwerk approach provided some insight into common methods used in this discipline.

The Orff approach has been used in the U.S. since the sixties and is broken down into four stages; imitation, exploration, literacy, and improvisation. "The natural behaviors of childhood singing, saying, dancing, playing, along with improvisation and creative movement form the basis of the Orff Schulwerk. Frequently referred to as elemental music making, the pedagogy is closely related to the child's world of play and fantasy, of games, chants, and songs" (Campbell \& Scott-Kassner, 2006, p.52). One of the unique developments in the Orff approach is the design of specialized instruments that enable students to easily explore creative rhythms and melodies. Improvisation being the highest level or goal of Orff, suggests that it is something that students must work their way up to by progressing through the stages, although it is conceivable for improvisation to occur in preliterate stages. (Campbell \& ScottKassner, 2006, p.53) 


\section{Play}

Play might be defined as an organized activity that is motivated by pleasure. Sometimes play is competitive. Play is for the most part, essential, serious fun. Play can be very structured with rules and deep strategies, such as those in the game of chess, or more loosely defined and open-ended, as a child might play with blocks, cars, or dolls. In a state of play, teaching and learning flow naturally, opening up opportunities for exploration and experimentation by all participants. (Isenbarger, State of Play 2009, p.v)

John Kratus suggests that there are seven levels of improvisation in music; exploration, process oriented improvisation, product oriented improvisation, fluid improvisation, structural improvisation, stylistic improvisation, and personal improvisation. Scott discusses the value of Kratus's model, "A model that I believe is compatible with the Orff Schulwerk approach is that of John Kratus....Since improvisation is developmental in nature (Azzara 2002), it is certainly possible for elementary students to make significant progress through many of these levels, but the first three levels are realistically attainable for most elementary-aged students when they are led through sequential activities in general music class" (Scott, 2007, pg.9).

Sequencing and guidelines along with development of skills and practice are thought to be necessary for students to be able to musically improvise at a higher level. Kratus's first level of improvisation, exploration, addresses the "play" aspect of improvisation.

Students discover the sounds they can make as they manipulate their instruments or voices through exploratory learning. No rules can be broken, because there are no rules to break. No notes are wrong, and expressiveness is at the heart of the improvisatory activity. Listening to a student explore sound is tricky and even occasionally unpleasant. At first their sounds usually don't even sound like music. The students are engaged in problem solving. The problem is learning how to create music. The solution is exploration. Students exploring in this way may stumble upon a sound or series of sounds without knowing the appropriate musical term, relevant music theory, or even the particular compositional technique they are using. Some students may explore a pattern and then a sequence and then sequence the pattern. Others may explore a rhythm and 
then displace the rhythm. Exploration - eventually - produces - improvisation. (Volz, 2005, pg. 50).

At first this level of exploration appears to be autonomous in nature, but Volz goes on to explain that certain parameters are necessary such as time limits, organization of small groups, order, and availability of instruments. Some examples of exploratory exercises described in this article are worth mentioning as they provide possible avenues for adaptation in the visual arts. Activities such as one note solos, duet improvisation, flash cards, assuming a character (drama), and the exquisite corpse (visual art) show that a cross curriculum approach to improvisation is possible.

State of Play: Divergent Methods for Creative Exchange was developed in cooperation with an Integrative Teaching International think tank which promotes identifying, teaching, and assessing visual thinking skills for today's designers. It includes a collection of activities that encourage play, collaboration, communication skills, and the learning of technical skills that ground study in art and design by introducing habits of mind that are the foundation for creative inquiry. The project suggests that "the teaching of art is more than the teaching of art. The lessons presented help students encounter and engage in authentic self-directed learning while simultaneously presenting base-line vocabulary and essential skills" (Isenbarger, State of Play 2009). 


\section{Parameters}

The structures within which teachers conduct the training of students with improvisation allow students to explore while maintaining a sense of classroom management and organization. Although it is important to provide guidelines, "too many parameters can squelch the students' creative nature and undermine the value of the task" (Volz, 2005, p.51). This seems to be somewhat of a gray area, but an important one that depends on the teachers comfort level. As I introduced activities with students during this project, I was careful only to apply a minimal number of parameters while aiming to provide a balance between the autonomy and heteronomy models. I was able to do this by introducing the lessons as games that had only a few basic rules. For example, during the problem finding exercise of systematic drawing, the students were not instructed to communicate any kind of idea with their pictures, but simply follow the instructions of adding the defined number of lines or shapes determined by the role of the dice. Some students did indeed create a structure of their own as the drawings developed, strategically formulating an objective composition while responding spontaneously to the stimuli. Each activity was designed to allow for the students to create their own structure, while working within a set of parameters.

Aside from the fact that improvisation in music and drama shares the elements of response and spontaneity, they also both encourage the aspect of exploration and skill development. In theater and drama training an actor engaged in improvisational activities would do so to improve his or her acting and thinking skills in performance, spontaneous expression, and confidence. In music, the musician trains in improvisation to be able to experience music as improvisation, communicate with other musicians, and improve performance skills. The teacher's role in the development of these skills would then be to allow for experimentation with parameters by encouraging exploration in play and fantasy, create opportunities for students to succeed, and monitor progress as they proceed through the stages. 


\begin{abstract}
Assessment
As stated earlier, one of the rationales for teaching with improvisation in music is to provide opportunities for musical assessment. Improvisation when considered developmental in nature allows for the evaluation of specific technical skills. "By observing a student's use of musical concept in improvisation, the teacher can follow up with questions about the student's musical intent and assess what remains to be covered with regard to that concept" (Scott, 2007, p.54). For example, as a student performs the teacher might listen for structure in repetition of patterns, listen for intent to match mental performance, and listen for tonal center as a student engages in exploratory improvisation (Volz, 2005, p.53). The improvisations themselves are not the focus of assessment but the skills drawn upon during the process are of importance. The history of debate centered on assessment in art education from selfexpression to discipline based art education is one that needs to be left alone here, but as mentioned earlier, innovative creative thinking and communication skills are at the center of this study.
\end{abstract}




\section{Meaning}

In her paper, "How Students Ascribe Meaning to Improvisation and Composition: rethinking

pedagogy in music education 2000”, Pamela Burnard draws some interesting conclusions from doctoral

research at the University of Reading.

Children should be encouraged to talk about, reflect upon, and write about (in reflective journals) their musical experiences in order to help make meaning of their learning. The findings of my study indicated that all children, irrespective of musical backgrounds, have the potential to think explicitly about their musical experiences. Thus teaching improvisation and composition should incorporate: (i) examining past and present assumptions about what it is to improvise and compose; (ii) encouraging children to be more reflective by asking children to think about how as well as what they improvise and compose; (iii) ensuring that starting points for improvising and composing are based on children's existing knowledge and experience; (iv) ensuring students have a wide range of instruments; (v) sufficient time for children to clarify conceptual modification or changes and to test and extend ideas through their actions and reflections; (vi) a clear distinction between critical appraisal and interpretation of improvised and composed outcomes; and (vii) opportunities for children to confer meaning on the creation of their own music and musical experiences. ( Burnard, 2000, p. 22).

This approach encourages students to reflect, ascribe meaning to, and think about how and what they create spontaneously. This works well in music education where a student can improvise within a structure and be fully immersed in the process of improvising, and it does provide some connections to visual art by getting students to think, reflect, talk about their experiences. 


\section{Chapter 4: Visual Thinking Strategies; Children and their Stories}

This chapter discusses the use of visual thinking strategies, and storytelling in this study as they

relate to the inclusion of the elements of spontaneity and improvisation in art. The issue of establishing a structure within which to determine any change in creative thinking and communication skills in the participants led to the inclusion of VTS in this study. The child's experience of art through the discussion of images, improvised narratives, and collaboration was intended to support the inclusion of improvisational elements into the study as well as to provide a framework for sequencing, guidelines, skill development, and assessment. 


\section{Visual Thinking}

Thinking calls for images, and images contain thought. Therefore the visual arts are a home-ground of visual thinking... To treat art as a form of visual thinking may seem unduly one sided. Art fulfills other functions, which are often considered primary. It creates beauty, perfection, harmony, order. It makes things visible that are invisible or inaccessible or born of fantasy. It gives vent to pleasure or discontent. None of this is denied here, but in order to fulfill such functions a great deal of visual thinking must be done... To make an object visible means to grasp its essential traits: one can depict neither a state of peace nor a foreign landscape nor a god without working out its character in terms offered by the image... Inversely, some of the objectives attributed to art are means of making visual thinking possible. Beauty, perfection, harmony, and orders do serve to give a sense of well-being by presenting a world congenial to human needs: but they are also indispensable conditions for making a cognitive statement clear, coherent, comprehensible. Aesthetic beauty is the isomorphic correspondence between what is said and how it is said. (Arnhiem, 1969 p. 254).

In this definition Arnhiem makes a distinction between art and visual thinking but also suggests the important relationship between them. Just as with any other form of communication such as verbal, music, or text, in order to relate a statement with the use of a visual language, thinking must occur. Our perceptions of the world, our experiences, and culture, have an impact on how we communicate. Visual Thinking Strategies thrives on the basis that people have different perceptions and encourages students to acknowledge those different perspectives and viewpoints while making sense of their individual world. 


\section{Children and their Stories}

A connection between improvisation, interpretation, and storytelling helped to shape the design of this study. The story or narrative which is prevalent in the art work of children helps them to make sense of visual images. The process of art criticism involves 4 actions. They are:

Describe - what things are in the painting? Think of things like clothing, environment, etc. Analyze how the elements of art (line, shape, form, texture, space, color and value) are used? How are the principles of unity pattern, rhythm, variety, balance, emphasis and proportion used? Interpret - what is the artist trying to say to you? What is going on in the picture or artwork? Judgment- What do I think about this artwork? Do I like it? Why or why not? The interpretation aspect of art criticism is the focus here. Description, analysis, and judgment are all important, but the stories of the images lie in the process of interpretation. Through guided classroom discussions during VTS training these other critical aspects were addressed but became evidential as the students aimed to reinforce their interpretations.

Research on children's development has often directed attention to what children do rather than what they say (researchers typically observe, record, and code behaviors: their gestures, performances on various tasks, solutions of problems). This is due to the predominance of behaviorism in mainstream psychology during most of this century, which posits that psychologists should concern themselves with people's actions rather than their words. Even when researchers are interested in what children have to say, it is often only because they want to know what children of a given age are capable of: can you think logically? Can they sequence events accurately? Can they remember a list of items? (Engle 1995 p. 8)

Children's art is often accompanied by a verbalization or a way of talking themselves through a drawing or painting to express an intention meaning or idea. By encouraging the student to take control or dictate what is happening as they create or respond to an image requires spontaneity and improvisation. The inclusion of improvisation into visual art in this study not only focused on the 
development of visual communication skills and creative thinking but also recognized the value and importance of the spoken and written word. "What children want to do is to talk to themselves in pictures, thereby weaving stories around the marks being made as a parallel to active fantasy play."

(Coates 2006 p.221)

Children not only tell stories to represent experience as they know it to be, as others know it to be, but they also tell stories to represent experience as they would like it to be. This is not simply a way of expression deep-seeded wishes or fantasies. The act of remarking your world serves a function in and of itself, beyond the expression of any conscious wishes. The imaginative control you gain over the world by being able to decide, at least symbolically, who does what to whom and what things look and sound like is itself vital component of human experience. (Engle 1995 p. 57). 


\section{Chapter 5: Findings and Conclusions}

This chapter discusses the observations and data analysis collected during the activities

conducted in this study a well as recommendations for future study in this area. Each activity will be described in detail and will include a brief summary of conclusions based upon its effectiveness and overall experience drawing from collected data, observations, student reflections, and example work.

1. Systematic Drawing

2. Shadow Puppets

3. Ricochet Critique: "I am the artist of this piece"

4. Story Starters

5. Visual Thinking Strategies

6. Pre and Post Writing Samples

7. Recommendations for future study 


\section{Systematic Drawing}

The inclusion of this activity addresses the aspect of problem finding versus problem solving as it relates to the five characteristics of improvisation as well as heteronomy. The objective was to challenge the students to make spontaneous artistic decisions while working within a set of parameters. To address and draw upon the improvisational aspects of play, this activity as with many of the others was introduced a game. A specialized pair of large dice was integral to the execution of this activity. I used a set of foam die one having the standard dots from one to six and the other having a different shape or line type on each face. (Square, circle, rectangle, free-form, triangle, choice of line type)

\section{Procedures}

Each student was given a large piece of white paper, colored markers, and a sharpie marker. The parameters of the game were then communicated to the students as follows; "Each of you will get two turns to roll the dice. When the dice are rolled, you along with your classmates will have ten seconds to incorporate the elements into your drawing. For example (demonstrating a roll of the dice) I rolled a 4 and a square. That means you would quickly draw 4 squares somewhere on your paper. Remember you only have ten seconds to draw." The class was informed that aside from these simple parameters they had complete freedom to approach this activity however they desired. After going around the room having each student roll the dice two times they were to add color to their pictures using markers. The students then were asked to voluntarily share their work with the class describing the choices they made. 


\section{Outcome}

The students provided positive feedback in general about this activity describing the experience as enjoyable. There was a general enthusiasm from most of the class as they asked if we could do this again the next day. After viewing the students' final works and listening to their rationales there appeared to be two distinct outcomes or approaches. Of the fifteen examples of works collected, five students approached this activity by randomly adding the shapes and lines to their paper with little development of a distinct idea during the process. The other students took more of a problem solving approach creating their own structure within the parameters of the activity as the random shapes and lines began to take on a meaning to them. Though the students demonstrated distinctly different types of thought, some simply responding to the stimuli and others creating a structure as they spontaneously responded to the stimuli, the overall outcome was successful in that the experience placed an emphasis on processes similar to ones used in the improvisation of music. At the conclusion of the activity the students provided some insight into their drawings when asked about what they had created. Below are some examples of the different approaches to the exercise. 


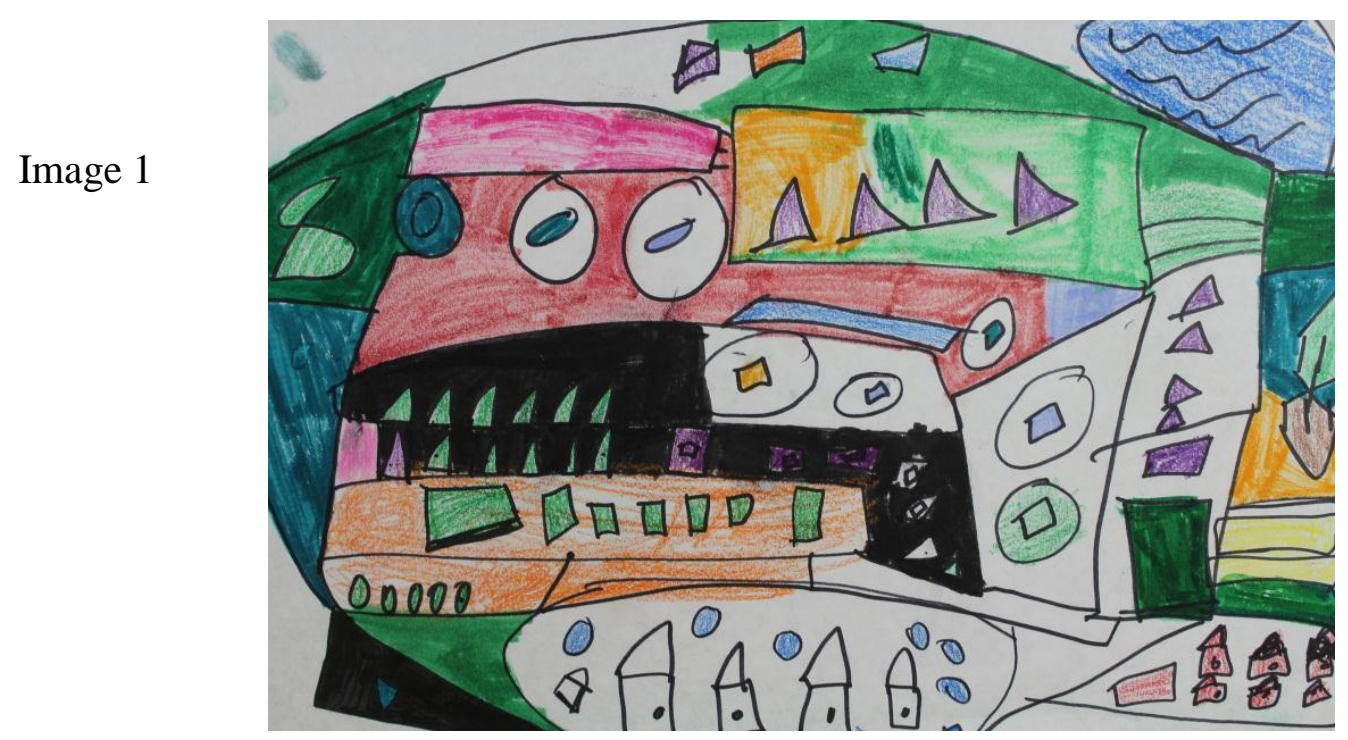

This example is one that took a completely problem finding approach to the activity. The student stated that she didn't pay much attention to where she placed elements until the end of the activity when she began adding color. She started seeing things that looked like buildings and houses. The picture was then no longer a composition of individual lines and shapes but took on the "feeling" of the summer camp she visited each year with tents and cabins and a lake. 


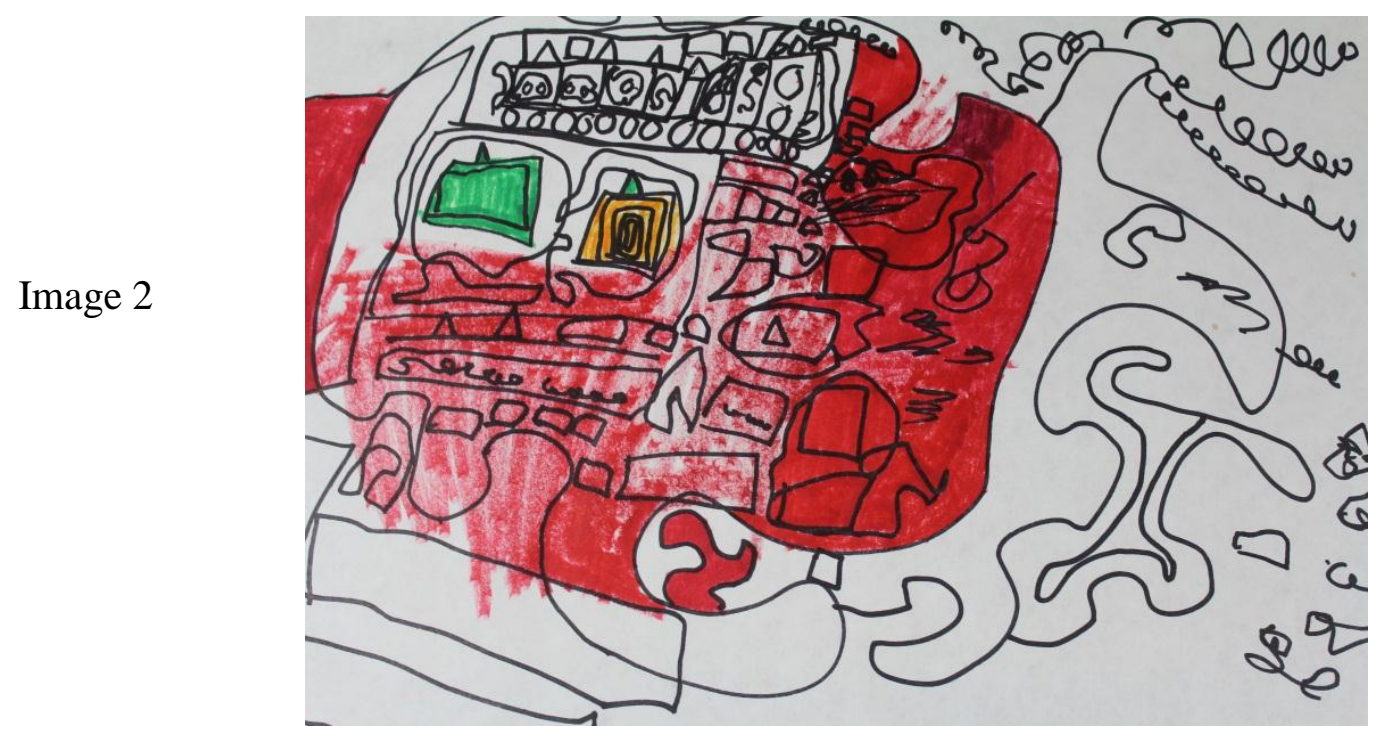

This example illustrates a combination of problem finding and problem solving approaches where the student said "At first I just started drawing the shapes and then I put six squares together and it looked kind of like a train so I tried to add things to it. Then when we got to choose lines I put the smoke coming out of the train. The train is going to crash." 
Image 3

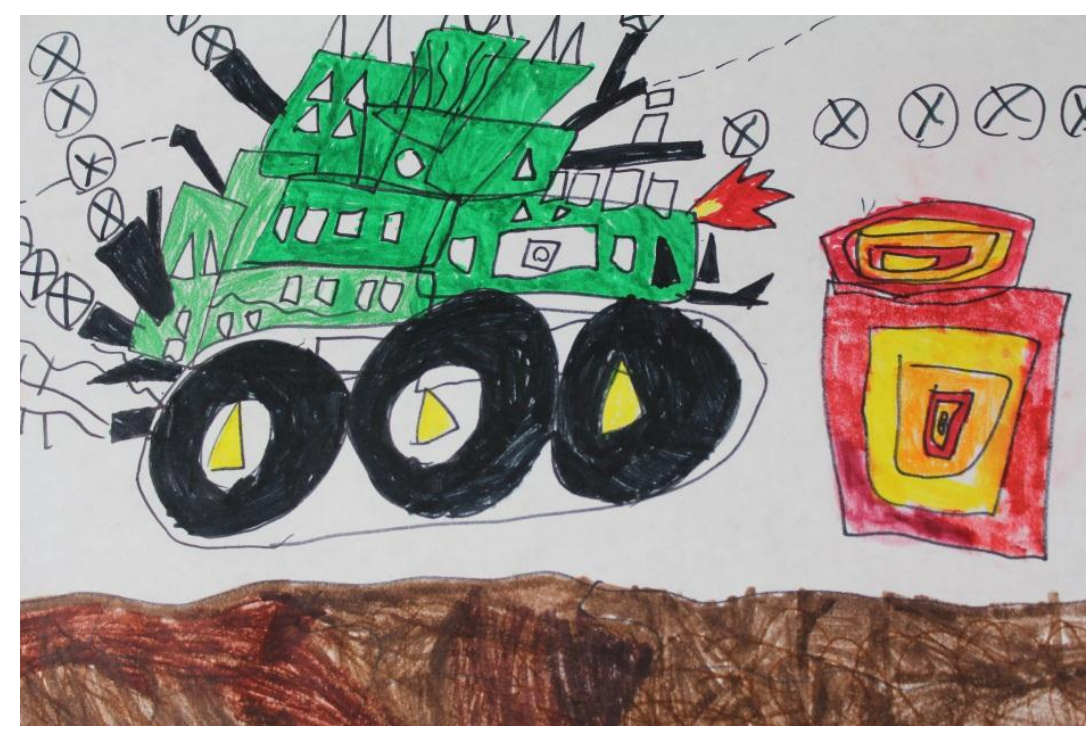

This is an example of an approach that very quickly became problem solving in nature. The student did not start out with a distinct subject matter for this but at any early stage in the activity had created this vehicle structure within which to work. This student was very enthusiastic with his description of the work. "At the beginning I wasn't sure what I was going to make, but I love tractors and monster trucks so that's what I ended up making. This is a battle tractor that's trying to kill a robot alien. I had to add lots of windows because of all the shapes we had to draw." 


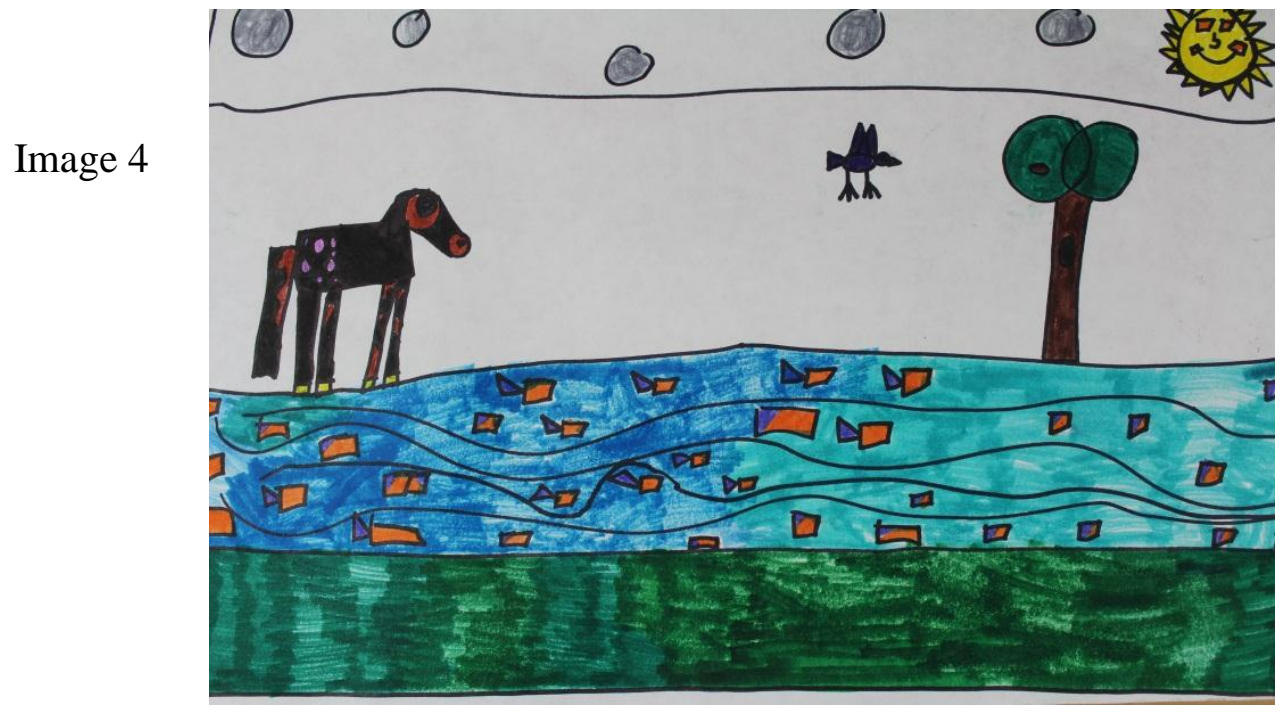

This example is one in which the student took the problem solving approach from the beginning, as she had a preconceived subject in mind but still had to make spontaneous decisions throughout the process. "I knew I wanted to make a horse, so I started with that but when I was done with the horse I still had to add shapes, so I made the river with lots of fish, then the sun, the clouds and a tree." 


\section{Shadow Puppets}

As improvisation in music and theater calls for the participant to spontaneously respond to a situation or stimuli, often the experience is inclusive of more than one participant. This particular activity addresses the aspect of collaboration, play, and communication through movement, music, and narrative. Just as musicians in a jazz ensemble or actors in an improv group would "play" off of each other, the students involved in the activity worked together, each having a specific role in the creation of an abstract large scale drawing. The students worked within a structure which provided particular materials and parameters that allowed them to make very free choices. The idea for this activity came from the instinctive desire for students to make shadow puppets in light of the digital projector I use in my classroom to show images during instruction.

\section{Procedures}

The parameters for this activity were introduced to students as a game. There was no formal demonstration conducted by the instructor aside from the relating aspects of the activity to the childhood game of musical chairs. The activity required the use of a digital projector, CD player, large 60X48 inch sheet of white paper, pencils, markers, and watercolor paint. Students were divided into pairs and teams, each team consisting of two pairs of students. The first pair of students acted as the shadow puppets and the other pair as the recorders. The other students in the class were engaged in a different regular curriculum activity so that I could monitor and observe the participants. As the game began I would turn on the CD player which contained a variety of music styles with a mixture of other sounds. The shadow puppet team would then respond to the music by casting a shadow with their hands onto the white paper. The idea was for them to "play" with the rhythms, melodies, and sounds creating a moving character of shadow a shape. I would present the 
students with approximately 60 seconds of time and then abruptly stop the CD player. The students would then freeze in place and the second team of "recorders" would trace the contour of the shadow shapes cast onto the paper with pencils. The students were instructed to try their best to hold still as the shapes were traced, but the recorders were inevitably challenged to trace a moving shape. The teams would then switch places and repeat the activity. After each pair cycled through twice I would take the paper down and turn it clockwise and have the next team take their turn. After the entire class had experienced this, they were given a choice of materials to add color to the drawing in groups of 6-8 students followed by a classroom discussion of the product.

\section{Outcome}

The collaboration aspect of this activity was challenging but successful. The experiment provided the opportunity for the students to discuss the characters they were creating in real time with each other, work together to make a record of the experience, and share imaginative interpretations of the product. Through observation I found that the interaction between the shadow characters was very polarized, meaning that there was either a very high or very low degree of interaction which I believe was dependent upon two factors. The individual personalities of the pairs of the students and the substance of the auditory stimulation were very influential on the outcomes. One pair of students for example would show signs of aggression between their shadow puppets; another pair would demonstrate a more respectful or gentle interaction, while others preferred a more autonomous approach depending on these factors.

An addition to these factors, the positive response to the experience of making these moving shadows with hands, light, and objects along with the exploration of space, form, movement, and rhythm produced a record of the experience that the students were eager to discuss. Following the 
VTS protocol, the formal discussion began with the questions: What is going on in this picture? What do you see that makes you say that? What else do you see? However, it is worth mentioning that preceding the formal discussion, during the process of adding color, the students began develop a narrative within the work on their own. As they painted they discussed lines, shapes, and areas of space as things began to take on meaning. As we discussed the final product, I realized that this particular discussion would be different than any of the other VTS sessions in that we were talking about an image that the students themselves had experienced and participated in the creation of.

Initially, the discussion centered on the experience of making the piece. Several students identified the contour shapes as hands moving around the paper in reference to the reaction to sound. As the discussion progressed, students tended to focus on specific areas of the piece picking out shapes or spaces that resembled organic and figurative elements. As I observed and mediated the discussion, I took paraphrased notes describing some of the students' more interesting reactions.

Student \#1: "There's these birds that escaped from their cage and knocked over a bunch of paint cans and got paint all over them and they are flying all around. They are all dizzy because they can't see and they are bumping into each other and making a mess"

Student \#2: “There's this little guy down there at the bottom and he's blue. I think he is yelling or signing really loud and making all this noise because he has his arms up and his grandmother is over there at the top "right" and she can't stand all the noise so she is telling him to be quiet and is trying to get away from him. I think it's his grandmother because she looks old and has her mouth open and her face is red."

Student \#3: "I see that guy too, the blue guy, but maybe he is a person who plays music or writes music and he is thinking about some music, which is all the colors and 
lines, and sees himself at a concert telling the musicians how to play it. That's him at the top too. He wants to be a star because he has a star in his eye"

Student \#4: "I think the guy with the star in his eye is having a nightmare about going to the fair and eating too much then going on too many rides and getting sick. And then this giant alien comes down and starts to attack."

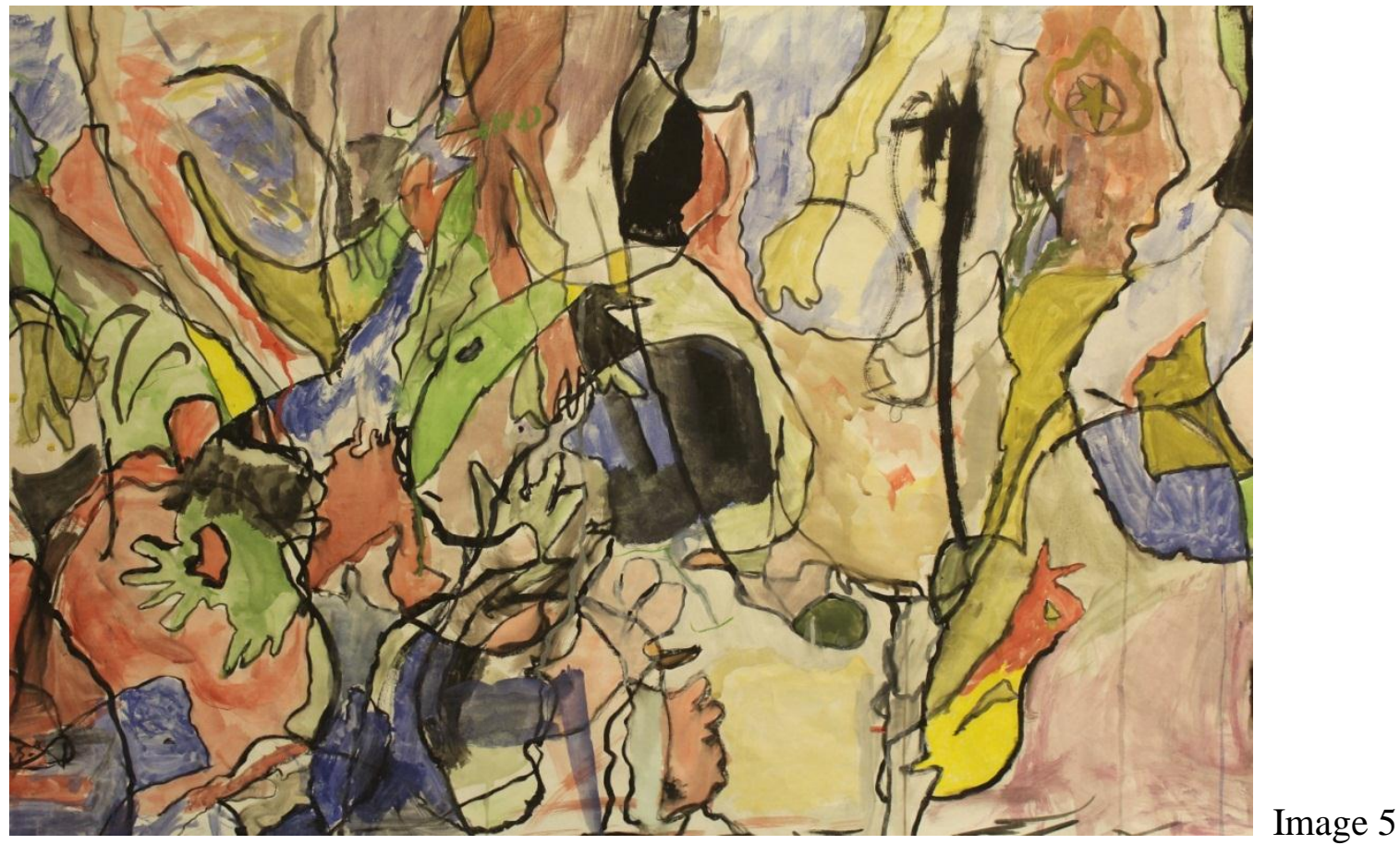




\section{Ricochet Critique; "I am the Artist of this Piece"}

The ricochet critique in this context is an activity that is performance based and closely related to skills developed through improvisation in the disciplines of drama and music, as the participant "acts" as the artist of an art work experiencing it in a novel way. As mentioned earlier, the use of improvisation in drama aims to develop acting and thinking skills in performance, spontaneous expression, and confidence. In music, the musician trains in improvisation to be able to experience music as improvisation, communicate with other musicians, and improve performance skills. Aspects of play and experimental improvisation proved to be encouraging motivators as the activity intended to challenge students to embrace the experience of an art work as the artist, improvising responses to questions from groups of students.

\section{Procedures}

The parameters of the activity were designed to allow students the freedom to experiment with the communication of narratives and to create a structure within which to interpret the work from the perspective of the artist spontaneously. The activity was again introduced as a game with the students separated into two groups of ten. Before the experiment began they were given an explanation of the parameters. First, I explained that the "artist" would have only one minute to look at a picture of the work to be discussed. They were to pick a poster up from a stack on the table, all face down, and study it for the given amount of time. During that time they were advised to try to come up with a title for the piece and decide what it was made out of. The stack of posters contained examples of a variety of media and subject matter such as abstract paintings, portraits, installations, sculptures, drawings, and prints. After the sixty seconds of study they were to place the example on the easel and present it to the group saying "I am the artist of this piece and I call it..." At this point 
the members of the group began asking the presenter questions about the work to which the "artist" would answer. The discussion would only take place as long as the student presenting felt comfortable. At the conclusion, the presenter would thank the group, the audience was advised to applaud, and then the next student would take his or her turn.

\section{Outcomes}

The success of this activity was dependent upon the participants' willingness to be open minded, take risks, and comfort level in speaking to the group. Throughout the study, the students' experiences with Visual Thinking Strategies had aimed to encourage them to be more confident with their interpretations, accept different points of view, and explore possibilities as we tried to make sense of images. Students who were not comfortable with the activity did not have to participate as the artist if they did not want to, but surprisingly, most were very eager to take their turn.

After observing and interviewing several students who participated in this activity, I found that the majority of participants described the experience as a positive one. The initial tensions and hesitation seemed to ease as the activity developed into more of an acting game. At first the students would present the work and answer the questions with very short concise answers without much elaboration, but as the students started to become more comfortable and familiar with the process they began to develop a complex structure. The turning point in the experiment arrived as one student began to embrace the character of the artist elaborating on detailed information about his life as an artist, where he was from, why he used certain materials, and why he chose the particular subject matter. At this point the students in the group began asking more detailed and poignant questions rather than yes or no questions. They began asking why, how, and who questions. The presenter even changed his voice and began speaking with an accent. As other students took their 
turns presenting, they built upon this structure, all speaking with accents and really having fun with the activity. The experience eventually became more about the student and his or her imaginary life as an artist then about the art work that was being presented.

The students were given a set of parameters during this activity that provided them with freedom to develop a structure within which to create. Communication, interpretive performance, spontaneity, and critical thinking skills were at the center of this activity making it one that embodied the purpose of the study. This experiment provided a link between skills that are developed through the use of improvisation in music and drama and the analytic, creative, imaginary, and emotional process of experiencing visual art. 


\section{Story Starters}

Throughout the study, stories and narratives served as an integral part of the process of adapting improvisation and the particular skills associated with it into visual arts education. This "story" approach aimed to encourage students to draw upon their own experiences and imaginations to make sense of images while responding to unexpected situations and making decisions. This particular activity aimed to reinforce the importance of the visual narrative as students were introduced to an online resource known as Scholastic Story Starters. This resource uses the idea of chance employing the use of a virtual machine that combines nouns, adjectives, verbs, and sentence fragments to create a surreal premise for a story. Throughout the study verbal communication of ideas in the form of classroom discussions and VTS sessions were most prevalent and addressed a more external type of improvisation. The connection between spoken and written word and the communication of stories through the use of visual images was the focus of this particular activity.

\section{Procedures}

The students were organized into groups of three and each group engaged the virtual story starter machine yielding a topic for their story. The parameters allowed for the students to choose from a variety of materials for their drawings such as pencils, pens, crayons, markers, and, oil pastels. The only direction given was that they were to visually illustrate a story about their character each student was responsible for a part of the story; the beginning, the middle, and the end. They were given time to discuss sequencing and events within their groups before they began drawing. 


\section{Outcomes}

The story starter resource produced results such as; “A jittery movie star that discovers a talking frog”, “An old Canada goose who hitch hikes across country", "A plaid elephant who only looks at things through a microscope", and "A nerdy dolphin that collects stamps." The outcome of this activity did not produce the results hoped for due to a number of factors. First, in this instance, not wanting to provide restrictive parameters or directions, the students created products that merely reflected the given subject without much elaboration or narrative detail. Secondly, this activity did not seem to be as engaging and perhaps needed to be more structured. The students took little time to discuss the topics and many began drawing immediately. In hindsight, requiring a certain amount of time for discussion may have yielded more interesting results. 


\section{Visual Thinking Strategies}

Improvisation in music and theater, as mentioned earlier, is often used as a tool to assess a particular skill within each discipline. In theater and drama training an actor engaged in improvisational activities would do so to improve his or her acting and thinking skills in performance, spontaneous expression, and confidence. In music, the musician trains in improvisation to be able to experience music as improvisation, communicate with other musicians, and improve performance skills. Visual Thinking Strategies teaches thinking through the discussion of images. "When we talk about art, our eyes and minds work together to combine perceptions, feelings, logic, memory, reason, imagination, and common sense. We draw on our experience as well as our creativity. We find language to express ideas that matter." (Housen, Yenawine, 2000, p. 2)

The partnership between improvisation and Visual Thinking Strategies during this study intended to enhance the students' experience of art works, improve skills such as communication, confidence, and self-expression, and to serve as the vehicle with which to investigate the outcomes of the study. Throughout the study VTS sessions were conducted between the experimental activities to build upon these skills. The goals as stated in the VTS Basic Manual Grades 3-5 are as follows:

1. To develop flexible and rigorous thinking skills, including observing, brainstorming, reasoning with evidence, speculating, cultivating a point of view, and revising.

2. To strengthen language and listening skills, including the willingness and ability to express oneself, respect for the views of others and the ability to consider and debate possibilities.

3. To develop visual literacy skills and personal connections to art, advancing one's ability to find meaning in diverse complex art.

4. To nurture problem-solving abilities, curiosity and openness about the unfamiliar 
5. To build self-respect, confidence and willingness to participate in groups discussions and process.

6. To apply VTS-supported skills in many contexts, both in school and out.

7. To extend one's experience with computers. (Housen, Yenawine, 2000, p. 3)

\section{Procedures}

The discussions, facilitated by the investigator were centered on three developmentally-based questions; "What is going on in this picture? What do you see that makes you say that? What else do you see? A list of the images 'VTS basic images grades 3-5' can be found in the appendix. The role of the teacher as the facilitator in VTS is a very important one. The training manual provides specific guidelines when conducting the lessons. They are as follows;

1. Ask the questions provided to initiate an active process of discovery and probing on the part of the students.

2. Listen carefully to and acknowledge every answer by looking with the students at the image, pointing to those details mentioned, and paraphrasing what students say.

3. Facilitate the discussion as it progresses, linking various converging and diverging opinions and helping students to synthesize a variety of viewpoints.

4. Encourage further inquiry, keeping the process open-ended and asking students to stretch and search for information beyond what they know. (Housen, Yenawine, 2000, p. 4-5)

These questions are meant to challenge the students to observe, speculate, and reason on the basis of evidence and served as guidelines for investigating narratives within the images. The question posed during the pre-post investigation asked the students to tell the story of the picture. The idea here was to 
test the effect of the improvisational activities and the VTS training sessions on the students thinking skills and abilities to create and decipher improvised narratives from images.

\section{Outcomes}

Through observation and facilitation of the discussions I was able to conclude that the students made progress in their ability to express ideas and points of view as well as in accepting and building upon the views of other students in the group. I believe this method of teaching thinking through art is a very effective one encouraging students to participate, have confidence, and keep an open mind. The enthusiasm and willingness to participate, alone was encouraging to me as a teacher and I plan to use this technique in the future. During a typical session, the students would initially draw upon their own personal experiences identifying with figures, situations, objects, and emotions. After observing and exploring, the students would begin to understand why they made these associations and after listening to other points of view, explore further possibilities. 


\section{Pre- Post Writing Samples}

The data used to investigate the effect of the activities on the thinking skills of the student participants involved in this experiment was collected in the form of writing samples. These writing samples were collected at the beginning of the study before any experience with the activities had occurred and then again at the end of the study. The pre and post samples were then analyzed by the investigator and two regular classroom teachers using the Six Continua for Assessing Thinking.

\section{Procedures}

As mentioned earlier, the 40 participants were divided into a control group and an experimental group in order to compare the results across the groups as well as within them. The students were shown a projected image during each collection process and were simply asked to write the story of the picture. Both groups were shown the same set of images as they corresponded to the particular sample collection. The first image used for the pre-experimental sample is shown below.

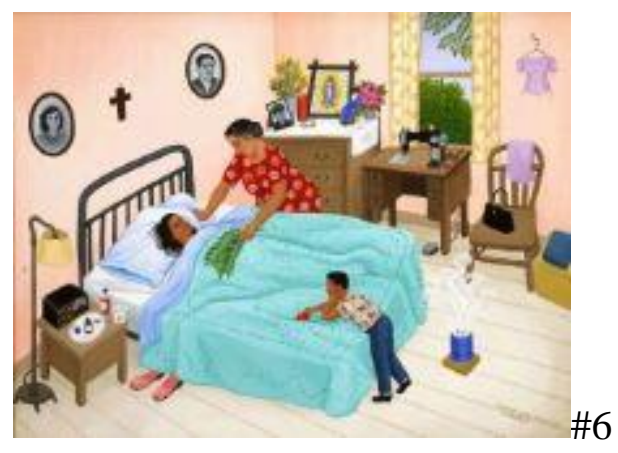

Carmen Lomas Garza. Curandera (Faith Healer). Oil on Linen mounted on wood, Collection of Mexican Museum, San Francisco, CA. c.1989 Carmen Lomas Garza. 
The Second image used for the Post experimental sample collection:

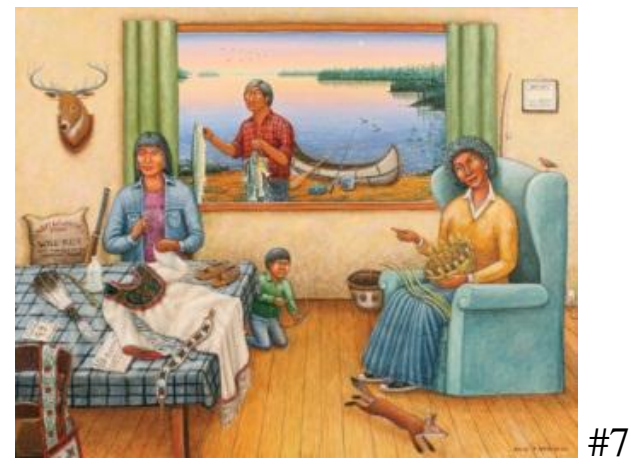

David Bradley. Chippewa Family. 1987. Acrylic on canvas, From the Collection of the Plains Art Museum, Fargo, ND.

In accordance with the WVU IRB, the students' names and identities were kept confidential. Each student was assigned a number by the investigator and the samples were kept in a secure location. The student numbers were later used to compare the preliminary samples with the post-experimental samples to identify any change. After all samples were collected from both the experimental and the control groups they were analyzed using the Six Continua for Assessing Thinking. This rubric assesses the perceived thinking of students by addressing aspects of thinking such as depth, clarity, dimensional thinking, restrictiveness, and insightfulness. Each sample would receive a number or scored based on the each of these aspects. (See Appendix: The Six Continua for Assessing Thinking) Due to the somewhat subjective nature of the assessments and the need to address any issues of bias, the samples in both groups were evaluated by the regular $4^{\text {th }}$ grade classroom teachers as well as the investigator. The scores were then averaged and compared.

\section{Outcomes}

The comparison within the experimental group showed some insignificant improvement in the assessment of the writing samples. The average score in this group for the preliminary assessment was 11.4. The average score in this group for the post experimental assessment was 12.42 showing an 
improvement of 1.089 points. Individually, the students showed some improvement as well. The charts located in the appendix show the scores recorded by the investigator and the teachers for each individual student. This information only shows the scores of students who were present for both the pre and post samples taken during the scheduled time. Unfortunately, there were several students in each group that missed either the pre or post sample collections and who's scores were unable to be compared. Each teacher's score is reflected showing the percentage of students who improved, showed no change, or dropped. One teacher's scores showed that $50 \%$ of students in the experimental group showed improvement, $28 \%$ showed no change, and $21 \%$ showed a drop. The other teacher's scores showed that $57 \%$ showed improvement, $14 \%$ showed no change, and $28 \%$ showed a drop.

The average score in the control group was significantly lower than that of the experimental group. Looking at the baseline scores of each group showed that the experimental group scored higher (11.4) than the control group (9.625). The overall score for the experimental group was 11.92 and the control group 8.29. Though this shows that the experimental group scores were much higher in general, if examined on an individual level the data also reveals that more students showed improvement in the experimental group than in the control group. In the control group one teacher's scores reflected that $33 \%$ showed improvement, $33 \%$ showed no change, and 33\% dropped. The other teacher's scores reflected that $42 \%$ showed improvement, $33 \%$ showed no change, and $25 \%$ dropped. 


\section{Conclusions}

The purpose of this study was to explore the idea of using elements of improvisation in visual art education to provide opportunities for children to experience art in a way that challenges them to be spontaneous, think critically, and develop communication skills. Through observations of these activities and the data collected, I believe that this research was beneficial to the students involved for a number of reasons. First, the enthusiasm of the participants involved in these activities that often times required them to step out of their comfort zone, experiment with new ways to solve problems, work together, respond spontaneously to unexpected situations, and experience art in a way that challenged them to think critically leads me to conclude that the experience was a valuable one. Students need to be engaged to learn and the aspects of play and experimentation and by introducing activities such as games provided key factors in the incorporation of these improvisation based activities into the discipline of visual art education.

Another aspect that affected the success or failure of the experiments conducted during this study was the development of activities that addressed the issue of autonomy versus heteronomy. The careful design of the parameters for each activity allowed for the students to create spontaneously within a structure but also allowed them to form their own structure within which to create was somewhat of a balancing act. If the parameters were too specific, outcomes would be somewhat predetermined lessening the child's ability to improvise. But if the parameters were not specific enough, centering more on the autonomy model, restrictions with respect to classroom environment such as classroom management, safety, and space would make the experience too chaotic to observe and execute.

Yet another factor which could be considered a positive outcome of the study was the adaptation of cross-disciplinary skills from music and drama as way of providing students with unique way of 
experiencing art. Due of the nature of improvisation, the study focused more on the child's experience of looking and talking about art rather than process of making it. The internalized improvisation that occurs in the art making process which was addressed in the activity of systematic drawing proved to be an interesting phenomenon, but one that is difficult to assess. This led the study in the direction of more performance based experiences where the students were given the opportunity to experience art as improvisation, communicate with other students about art, and experience art in the context of performance. Throughout this study the constant struggle of finding avenues to explore improvisation in the context of visual art led to the conclusion that it has value in art education, but in order to be studied, its nature required the inclusion of performance and communication skills inherent in the disciplines of music and drama. 


\section{Recommendations for future Study}

There are several factors or modifications that could be considered for further investigation of this topic. Improvisation in both music and drama focuses on the development of discipline specific skills and serves as a way to assess those skills in a progressive manner building upon previous knowledge learned at sequential levels and stages. Three points of discussion centering on visual materials, assessment, and methods of observation and data collection would be important in the development of future research in this area.

\section{Visual Materials}

To serve as a more advanced stage of the study of improvisation in art education following the model described in this study, the use of images that provide the viewer more opportunity to imagine and less reliance on literal translation would be beneficial. The images used for data collection of the writing samples were both very and representational as they depicted figures in a domestic space. The reason these images were used was to encourage the viewer to draw upon personal experience and knowledge to help formulate a narrative. But, showing the students abstract paintings by Kandinsky for example, and asking them to write the story of the picture would have perhaps provided more interesting results and could be considered for future investigation.

\section{Assessment}

The use of Visual Thinking Strategies played an integral part in the study encouraging students to open up and feel more comfortable speaking in front of a group. VTS partnered with the activities 
developed for this research provided for a positive and innovative experience of art for the participants of the study, but the focus of assessment on writing skills needs to be reconsidered. The assessment of improvisations in music and drama is more about the assessment of particular skills rather than the improvisations themselves. One fault of the design of this study lies in the distinction between the actual skills that were assessed and the skills that were drawn upon during the experiments that were conducted. It could be argued that the thinking skills used to write and the thinking skills used to communicate verbally are similar but not the same. The cognitive skills required to process perceptions, ideas, and emotions may be similar, but the way we speak often times differs from the way we write especially at a younger age. For this reason, and because of the nature of improvisation being more performance based, the writing component did not serve its purpose as well as a verbally communicated sample would have.

Assessing the thinking skills through the spoken word would help to create a more concrete relationship between the activities and Visual Thinking Strategies eliminating any creative limitations that could possibly be associated with the written responses, therefore generating a more accurate representation of what is actually learned. The investigator would be provided with a whole new set of skills and data to consider such as, vocal inflection, speaking rate, use of new vocabulary terms, and a more complete view of the thought process. To take this one step further, the assessment could also include a visual component via video recordings to assess skills in performance, such as body language, interactions between participants, and non-verbal communication. For example, during the "I am the Artist of this Piece" activity, this information would very valuable as the participants embraced the role of the artist changing their voices, improvising responses to the audience, embellishing, and telling made up stories. This activity really embodied the whole idea behind the project, but the impact it had on the overall outcome I believe was lost due to the methods of data collection. 


\section{Methods of Observation and Data Collection}

To further investigate improvisation in art education, it is recommended that the investigator alter the methods of data collection for the purposes of more consistent assessment. With the recommendation of assessing the thinking skills used to create improvised interpretive narratives being better suited to verbal communication for the purposes of future study in this area, it is suggested that the investigator collect audio and or visual samples of the students' responses and utilize transcriptions of the audio for assessment using more of a performance based rubric. It is also suggested that the timeframe with which to investigate certain activities be extended, along with the modification and inclusion of other activities be considered. Though the experimental activities conducted were successful, in that they provided the participants with opportunities to improvise within the context of visual art, it is also recommended that the initiation of activities that focus more on the creation of content rather than ones that provide the content be considered. It is recommended that activities such as the "story starter" be replaced with exercises that provide the children more freedom to create narratives without predisposed subject matter. For example, instead of providing the premise for a story with words, have the students participate in group story telling sessions about images, each responding to the previous input provided by other members of the group.

In conclusion, I believe that using improvisation, spontaneity, and visual thinking strategies in art education can be a viable way of challenging students to think, communicate, and explore possibilities. Experimentation encourages creativity and as a teacher I am always looking for new ways to engage my students. If nothing else, the ideas explored in this study have proven to be ones that motivate students to take risks, think on multiple levels simultaneously, and be more open minded while providing them with an experience of art that is challenging, innovative, and enjoyable. 


\section{Bibliography}

Arnhiem, Rudolf. Visual Thinking. University of California Press Ltd. London, England 1969

Burnard, Pamela. How Children Ascribe Meaning to Improvisation and Composition: rethinking pedagogy in music education. Music Education Research, Mar2000, Vol. 2 Issue 1, p7-23

Campbell, Patricia; Scott-Kassner, Carol. Music in Childhood: From Preschool through the Elementary Grades. Third Edition, Thompson and Schermir. California 2006.

Coates, Elizabeth; Coates, Andrew. Young children talking and drawing. International Journal of Early Years Education, Oct2006, Vol. 14 Issue 3, p221-241

Cyrs, Thomas E. Visual thinking: Let them see what you are saying. New Directions for Teaching \& Learning, Fall97, Issue 71, p27

Engle, Susan. The Stories Children Tell: making sense of the narratives of childhood. W.H. Freeman and Company 1995

Hodgson, John; Richards, Ernest. Improvisation. Harper and Row Publishers. London. 1966.

Housen, Abigale; Yenawine, Phillip. Visual Thinking Strategies, Basic Manual: Grades 3-5. Visual Thinking in Education, 2000

Isenbarger, Stacy (editor). State of Play. Retrieved from website, www.inegrativeteaching.org. 2009

Johnstone, Keith. Impro: Improvisation and the Theater. Routledge Theater Arts Books. New York, NY 1979

Koutsoupidou, Theano. Improvisation in the English primary music classroom: teachers' perceptions and practices. Music Education Research, November 2005, Vol. 7, No.3, pp. 363-381 
Locke, June; Ossont, Sharon. "Playing" Stories: Creative Drama and Children's Literature. Book Links, May2007, Vol. 16 Issue 5, p43-46

Longhenry, Susan. Thinking Through Art at the Boston Museum of Fine Arts: School Arts. Mar2005, Vol. 104 Issue 7, p56-57

Monk, Augusto. Music Makers Improvisation; Improvisation and Cognition. Canadian Music Educator, Fall 2010, Vol.52 number 1. Pages 40-41.

Pearse, H. (1983). Brother, can you spare a paradigm? The theory beneath the practice. Studies in Art Education, (1983). 24(3), 158-163.

Peters, Gary. Can Improvisation be Taught? International Journal of Art \& Design Education, Oct2005, Vol. 24 Issue 3, p299-307

Rzewski, Frederic. On Improvisation. Contemporary Music Review, 2006, Vol. 25 Issue 5/6, p491-495

Sawyer, R. Keith. Improvisation and the creative process: Dewey, Collingwood, and the aesthetics of spontaneity. Journal of Aesthetics \& Art Criticism, Spring2000, Vol. 58 Issue 2, p149

Scott, Julie K. Me? Teach Improvisation to Children? General Music Today, Winter2007, Vol. 20 Issue 2, p6-13, 8p

Spolin, Viola. Improvisation for the Theater; A Handbook of Teaching and Directing Techniques. Northwestern University Press. Evanston, IL 1977.

Stone, Sandra J.Chakraborty, Basanti. Process versus Product. Childhood Education, Spring, 2011, Volume: 87, Issue: 3 
Tishman, Shari. Artful Thinking Final Report. Retrieved from website, www.pz.harvard.edu/research/ArtfulThinkingFinalReport.pdf. 2006

Volz, Micah D. Improvisation Begins with Exploration. Music Educators Journal, Sep2005, Vol. 92 Issue 1, p50-53

Wright, Cheryl; Bacigalupa, Chiara; Black, Tyler; Burton, Michael. Windows into Children's Thinking: A Guide to Storytelling and Dramatization. Early Childhood Education Journal, Feb2008, Vol. 35 Issue 4, p363-369 


\section{Appendices}

\section{\#1 The Six Continua for Assessing Thinking}

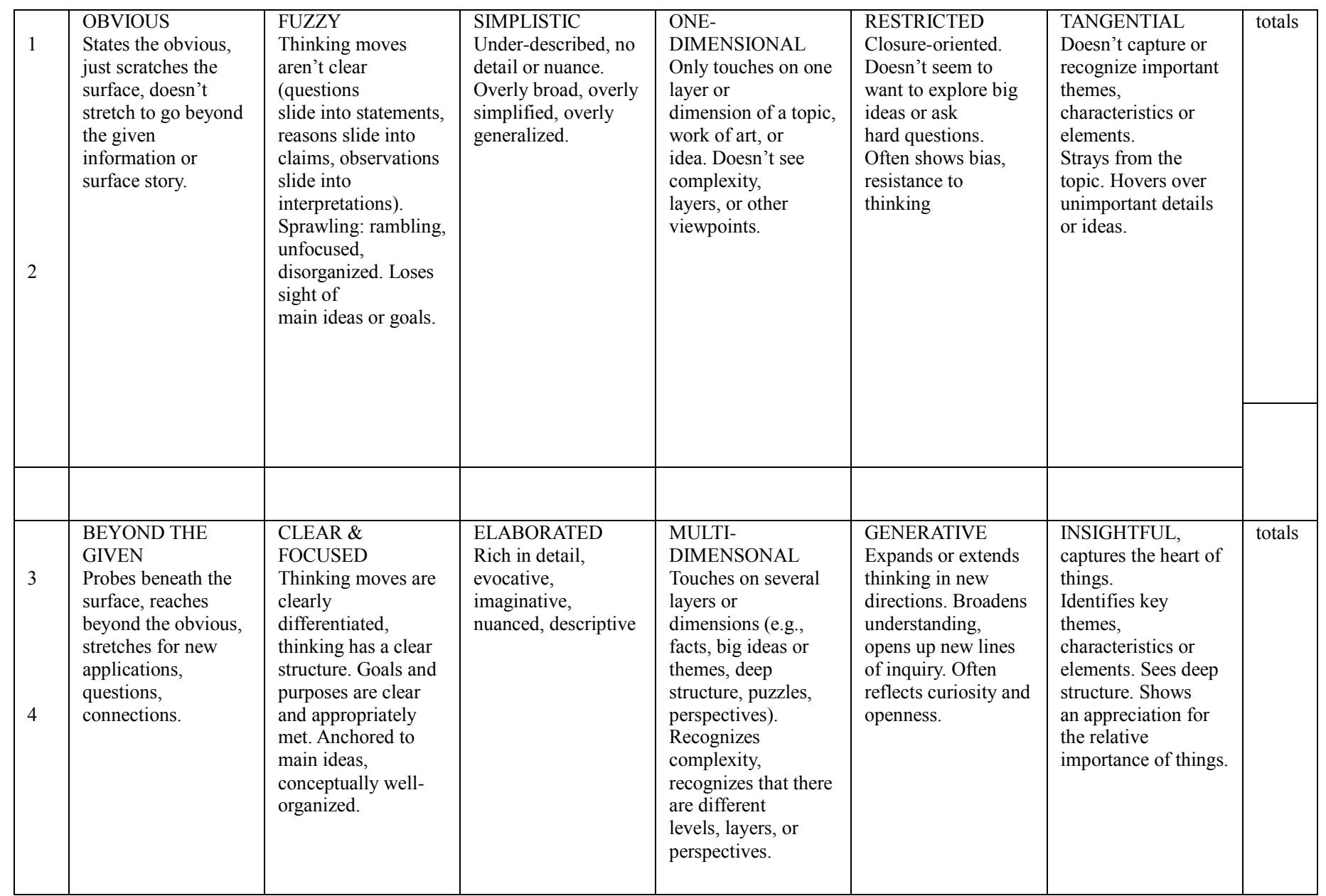


\#2 Results of Sample Analysis: Experimental Group 50\% improvement vs. 57\% improvement

\begin{tabular}{|c|c|c|c|c|c|c|c|}
\hline \#participant & $\begin{array}{l}\text { Sample } \\
1\end{array}$ & $\begin{array}{l}\text { Sample } \\
2\end{array}$ & Totals & \#participant & $\begin{array}{l}\text { Sample } \\
1\end{array}$ & $\begin{array}{l}\text { Sample } \\
2\end{array}$ & Totals \\
\hline 1 & 15 & 16 & +1 & 1 & 12 & 11 & -1 \\
\hline 2 & 15 & 16 & +1 & 2 & 13 & 13 & 0 \\
\hline 3 & 14 & 14 & 0 & 3 & 13 & 13 & 0 \\
\hline 4 & 9 & 11 & +2 & 4 & 11 & 8 & -3 \\
\hline 5 & 7 & 7 & 0 & 5 & 6 & 7 & +1 \\
\hline 6 & 12 & 14 & +2 & 6 & 11 & 14 & +3 \\
\hline 7 & 6 & 6 & 0 & 7 & 7 & 8 & +1 \\
\hline 8 & 8 & 7 & -1 & 8 & 7 & 9 & +2 \\
\hline 9 & 14 & 11 & -3 & 9 & 15 & 13 & -2 \\
\hline 10 & 14 & 16 & +2 & 10 & 9 & 14 & +5 \\
\hline 11 & 16 & 19 & +3 & 11 & 17 & 15 & -2 \\
\hline 12 & 9 & 18 & +9 & 12 & 10 & 17 & +7 \\
\hline 13 & & & & & & & \\
\hline 15 & 7 & 7 & 0 & 15 & 6 & 7 & +1 \\
\hline 16 & 18 & 16 & -2 & 16 & 19 & 21 & +2 \\
\hline \multicolumn{4}{|c|}{$50 \%$ Improvement } & \multicolumn{4}{|c|}{ 57\% Improvement } \\
\hline \multicolumn{4}{|c|}{$28 \%$ No change } & \multicolumn{4}{|c|}{$14 \%$ No change } \\
\hline \multicolumn{4}{|c|}{$21 \%$ Drop } & \multicolumn{4}{|c|}{$28 \%$ Drop } \\
\hline
\end{tabular}


\#3 Results of Sample Analysis Control Group: 33\% Improvement vs. 42\% Improvement

\begin{tabular}{|c|c|c|c|c|c|c|c|}
\hline Participant \# & $\begin{array}{l}\text { Sample } \\
1\end{array}$ & $\begin{array}{l}\text { Sample } \\
2\end{array}$ & Totals & Participant \# & $\begin{array}{l}\text { Sample } \\
1\end{array}$ & $\begin{array}{l}\text { Sample } \\
2\end{array}$ & Totals \\
\hline 1 & 6 & 6 & 0 & 1 & 7 & 6 & -1 \\
\hline 2 & 9 & 10 & +1 & 2 & 7 & 9 & +2 \\
\hline 3 & 8 & 7 & -1 & 3 & 11 & 12 & +1 \\
\hline 4 & 12 & 9 & -3 & 4 & 9 & 10 & +1 \\
\hline 5 & 6 & 6 & 0 & 5 & 7 & 6 & -1 \\
\hline 7 & 6 & 6 & 0 & 7 & 6 & 6 & 0 \\
\hline 9 & 15 & 16 & +1 & 9 & 13 & 13 & 0 \\
\hline 11 & 8 & 6 & -2 & 11 & 10 & 7 & -3 \\
\hline 12 & 14 & 18 & +4 & 12 & 12 & 13 & +1 \\
\hline 14 & 6 & 6 & 0 & 14 & 6 & 7 & +1 \\
\hline 15 & 14 & 12 & -2 & 15 & 17 & 16 & -1 \\
\hline 16 & 10 & 11 & +1 & 16 & 12 & 12 & 0 \\
\hline
\end{tabular}

Improvement 33\%

No Change $33 \%$

Drop 33\%
Improvement 42\%

No Change $33 \%$

Drop 25\% 


\section{\#4 Writing Sample Examples Experimental Group}

Image \#1

$\# 1$

Once upon a time there was a girl and she was really sick. She had a brother and a mother and her mother gave her hot chocolate but she didn't want it. Her brother was sad if she was going to die. And the next day her mother fixed and tried to get her to eat but she didn't eat a single bite. Then it was lunch time and she still didn't eat. Then it was dinner and she still didn't eat a single bite. Then her mom called the hospital and they tried to fix her and when they came out with her she was much better. So they took her home she said she was hungry so she ate all the leftovers.

\begin{tabular}{|l|l|l|l|l|l|l|}
\hline & & & & & & total \\
\hline
\end{tabular}

\#2

Once upon a time there was a girl in bed that was sick. Her mom gave her medicine but it didn't work so she called her son and said what can we do? He said maybe we can take her to the doctor. The girl said what if he can't help? We will have to take you to the hospital. But I don't want to go. You have to. Fine I will just to get better. Then every day she had to take medicine.

\begin{tabular}{|l|l|l|l|l|l|l|}
\hline & & & & & & total \\
\hline
\end{tabular}

\#3

The guy is sick because he's been playing outside for a long time. His mom is trying to help her son feel better. She is trying not to get her son sick again. His younger brother is worried that his brother will die. But his brother is feeling better than ever. Next time he won't play outside when it's going to rain or when the wind is blowing hard or something.

\begin{tabular}{|l|l|l|l|l|l|l|}
\hline & & & & & total \\
\hline
\end{tabular}


In the picture there was a young girl who was sick and there was an old lady that was walking to town. And that old lady and the young girl bumped into each other and they walked to town together talking about themselves. And when she heard the young girl cough she asked if she was sick and the young girl said yes and the old lady said to come back home and took her up to the extra bedroom. It was more like a guest room but now it is being used. And so she took her temperature and it was 100.48 and she said you are really sick. And so she rushed downstairs into her bathroom and she got some medicines and a spoon and measuring cup and glass of water. She said to take this and then "granls" gargle? some water and you will get better soon.

\begin{tabular}{|l|l|l|l|l|l|l|}
\hline & & & & & total \\
\hline
\end{tabular}

\#5 The girl that was sick

This woman doctor was very sick she had to take her upstairs to put her to bed. She had to take medicine. Her mom put stuff in the trash can that made stress go away. She felt a little better but not a lot. The next morning she felt better and played outside with her brother.

\begin{tabular}{|l|l|l|l|l|l|}
\hline & & & & & total \\
\hline
\end{tabular}

\#6

A little boy's mother is sick in bed. The little boy's name is Joseph. Joseph's father died when Joseph was 2 . He doesn't want to lose his mother too. His grandmother moved in once his mother got sick. His grandmother sent him outside to fetch some red berries called heeling berries. Joseph was happy to help. When he got back his mother was having a coughing fit. It was beginning to get dark. Joseph's grandmother sent to bed. When he woke up it was 10:00 in the morning. He leaped out of be ready to help his grandmother. But his grandmother said "go back to bed your mother will be fine."

\begin{tabular}{|l|l|l|l|l|l|}
\hline & & & & & total \\
\hline
\end{tabular}

\#7

There is a family a boy a girl and mom. The mom is tucking the girl in while the boy watches them. The family believes in god. It's a little windy outside. There are two pictures hanging on the wall. There is an old sewing machine. In the background there are trees and bushes outside. They are black.

\begin{tabular}{|l|l|l|l|l|l|l|}
\hline & & & & & & total \\
\hline
\end{tabular}




\section{\#5 Writing Samples Experimental Group}

Image \#2

$\# 1$

Pa was fishing in Salmon Lake. Ma was patching her daughter May's dress. May was in her room waiting for her dress to be done. Sam, May's little brother, was chasing their pet fox, Red. Grandmother was weaving a basket that her Indian friends had showed her how to do. The head of a buck Pa shot was hanging above Pa's gun and Ma's sack of wheat. Pa had just gotten back from catching two huge fish. Ma had just started on May's sleeve. Grandmother was almost done wither her basket. When she was done she would pick berries and put them in her basket. Sam and Red were having a great time.

\begin{tabular}{|l|l|l|l|l|l|}
\hline & & & & & total \\
\hline
\end{tabular}

\#2

The father just got a fish and the lady is sewing and the boy is hunting the fox and the grandma is weaving a basket. It looks like the boy is hunting his pet and his mom is telling the boy don't shoot at the fox. The da might have a gun so he can hunt deer and birds. The lady is making hunting clothes. The boy is probably waiting for his dad to come home and take him hunting. And the fox is running for his life.

\begin{tabular}{|l|l|l|l|l|l|l|}
\hline & & & & & & total \\
\hline
\end{tabular}

\#3

One day Low the little boy, his mom, dad, and grandma were camping. His dad went fishing and his mom was making a dress for the party tonight. His grandma was making baskets for the food. Dad said, Low, come out and help me with the fish. At 8:00 it was time for the party and friends and family were there. Then at 12:00 everybody went home. Low's dad and mom tucked him in he went to sleep.

\begin{tabular}{|l|l|l|l|l|l|l|}
\hline & & & & & total \\
\hline
\end{tabular}


Back a long time ago there were two women a boy and one man. One lady liked to make shirts and the other girl liked to make baskets. The little boy was hunting and the man was fishing and he caught a lot of fish. And he went home and told them so they had a cookout with all their friends. But got to the phone they remembered that they had no friends and then they said we're friends so they had their cookout together.

\begin{tabular}{|l|l|l|l|l|l|l|}
\hline & & & & & & total \\
\hline
\end{tabular}

\#5

There are 4 people, 2 women and 2 men. The men as if they like to go hunting and fishing. They look like they are native Americans. One of the boys is chasing a fox. The other boys has just got back from a fishing trip and has some fish in his hand. One of the women is making a basket, the other woman is knitting shirt.

\begin{tabular}{|l|l|l|l|l|l|l|}
\hline & & & & & & total \\
\hline
\end{tabular}

\#6

Once upon a there was a family that went on a trip to the cabin and a fox had gotten in. The little boy was going to shoot it but his grandma said no that he could not shoot it and so he was very sad. His grandma said there is no need to be sad we can go fishing if you would like and he said yes. So they went to the lake across from the cabin and they started fishing and back home his mom was sewing a dress and his grandma was making many baskets. Then his mom and grandma started to make dinner and then it was time to come back in from fishing. They came back in got cleaned up and washed their hands and all sat down to eat dinner.

\begin{tabular}{|l|l|l|l|l|l|}
\hline & & & & & total \\
\hline
\end{tabular}

